NBER WORKING PAPER SERIES

\title{
CROP DISEASE AND AGRICULTURAL PRODUCTIVITY
}

\author{
Christine L. Carroll \\ Colin A. Carter \\ Rachael E. Goodhue \\ C.-Y. Cynthia Lin Lawell \\ Working Paper 23513 \\ http://www.nber.org/papers/w23513
NATIONAL BUREAU OF ECONOMIC RESEARCH
1050 Massachusetts Ave
Cambridge MA 02138
June 2017

We thank Krishna V. Subbarao, Julian Alston, Andre Boik, Colin Cameron, Erich Muehlegger, Kevin Novan, Peter Orazem, John Rust, Wolfram Schlenker, Paul Scott, Dan Sumner, Sofia Villas-Boas, Marca Weinberg, Jim Wilen, and Jinhua Zhao for invaluable discussions and comments. We also received helpful comments from seminar participants at the University of California at Davis and California State University at Chico, and from conference participants at the NBER Understanding Productivity Growth in Agriculture Research Conference, the Heartland Environmental and Resource Economics Workshop, the Association of Environmental and Resource Economists (AERE) Summer Conference, the American Agricultural Economics Association (AAEA) Annual Meeting, the Giannini Agricultural and Resource Economics Student Conference, and the Interdisciplinary Graduate and Professional Student (IGPS) Symposium. We received funding from USDA NIFA (grant \# 2010-51181-21069). We also benefited from valuable discussions with Tom Bengard, Bengard Ranch; Kent Bradford, Seed Biotechnology Center UC-Davis; Leslie Crowl, Monterey County Agricultural Commissioner's Office; Rich DeMoura, UC-Davis Cooperative Extension; Gerard Denny, INCOTEC; Lindsey du Toit, Washington State University; Thomas Flewell, Flewell Consulting; Hank Hill, Seed Dynamics, Inc.; Steve Koike, Cooperative Extension Monterey County; Dale Krolikowski, Germains Seed Technology; Chester Kurowski, Monsanto; Donald W. McMoran, WSU Extension; Marc Meyer, Monsanto; Chris Miller, Rijk Zwaan; Augustin Ramos, APHIS; Scott Redlin, APHIS; Richard Smith, Cooperative Extension Monterey County; Laura Tourte, UC Cooperative Extension Santa Cruz County; Bill Waycott, Monsanto; and Mary Zischke, California Leafy Greens Research Program. Carter, Goodhue, and Lin Lawell are members of the Giannini Foundation of Agricultural Economics. All errors are our own. The views expressed herein are those of the authors and do not necessarily reflect the views of the National Bureau of Economic Research.

NBER working papers are circulated for discussion and comment purposes. They have not been peer-reviewed or been subject to the review by the NBER Board of Directors that accompanies official NBER publications.

(C) 2017 by Christine L. Carroll, Colin A. Carter, Rachael E. Goodhue, and C.-Y. Cynthia Lin Lawell. All rights reserved. Short sections of text, not to exceed two paragraphs, may be quoted without explicit permission provided that full credit, including $(\mathcal{C}$ notice, is given to the source. 
Crop Disease and Agricultural Productivity

Christine L. Carroll, Colin A. Carter, Rachael E. Goodhue, and C.-Y. Cynthia Lin Lawell NBER Working Paper No. 23513

June 2017

JEL No. Q00,Q10,Q12

\section{$\underline{\text { ABSTRACT }}$}

Crop diseases and how they are managed can have a large impact on agricultural productivity. This paper discusses the effects on agricultural productivity of Verticillium dahliae, a soil borne fungus that is introduced to the soil via infested spinach seeds and that causes subsequent lettuce crops to be afflicted with Verticillium wilt. We use a dynamic structural econometric model of Verticillium wilt management for lettuce crops in Monterey County, California to examine the effects of Verticillium wilt on crop-fumigation decisions and on grower welfare. We also discuss our research on the externalities that arise with renters, and between seed companies and growers due to Verticillium wilt, as these disease-related externalities have important implications for agricultural productivity.

Christine L. Carroll

College of Agriculture

CSU Chico

940 West First Street

Chico, CA 95929

clcarroll@csuchico.edu

Colin A. Carter

University of California at Davis

Agricultural and Resource Economics

One Shields Avenue

Davis, CA 95616

colin@primal.ucdavis.edu
Rachael E. Goodhue

University of California at Davis

Agricultural and Resource Economics

One Shields Avenue

Davis, CA 95616

goodhue@primal.ucdavis.edu

C.-Y. Cynthia Lin Lawell

University of California at Davis

Agricultural and Resource Economics

One Shields Avenue

Davis, CA 95616

cclin@primal.ucdavis.edu 


\section{Introduction}

Crop diseases can have a large impact on agricultural productivity. Invasive plant pathogens, including fungi, cause an estimated $\$ 21$ billion in crop losses each year in the United States (Rossman, 2009). Verticillium dahliae is a soil borne fungus that is introduced to the soil via infested spinach seeds and that causes subsequent lettuce crops to be afflicted with Verticillium wilt (V. wilt). Lettuce is an important crop in California, and the majority of the lettuce production in the United States occurs in California. The value of California's lettuce crop was $\$ 1.7$ billion in 2013 (National Agricultural Statistics Service, 2015).

How crop diseases are managed can have a large impact on agricultural productivity as well. V. wilt can be prevented or controlled by the grower by fumigating with methyl bromide, planting broccoli (a low-return crop), or not planting spinach. These control options entail incurring costs or foregoing profit in the current period for future benefit. V. wilt can also be prevented or controlled by the spinach seed company by testing and cleaning the spinach seeds. However, seed companies are unwilling to test or clean spinach seeds, as they are not affected by this disease.

This paper analyzes the effects of $\mathrm{V}$. wilt on agricultural productivity. In particular, we use a dynamic structural econometric model of $\mathrm{V}$. wilt management for lettuce crops in Monterey County, California to examine the effects of V. wilt on crop-fumigation decisions and on grower welfare. We also discuss our research on the externalities that arise with renters, and between seed companies and growers due to $\mathrm{V}$. wilt, as these disease-related externalities have important implications for agricultural productivity.

We use a dynamic model for several reasons. First, the control options (fumigation, planting broccoli, and not planting spinach) require incurring costs or foregoing profit in the current period for possible future benefit, and are thus are best modeled with a dynamic model. ${ }^{2}$ Second, because cropping and fumigation decisions are irreversible (as is the damage

\footnotetext{
${ }^{2}$ Some of these actions may also generate benefits in the current period for the current crop. For example, in addition to being an investment in protecting potential future lettuce crops from V. wilt, methyl bromide
} 
from $\mathrm{V}$. wilt), because the rewards from cropping and fumigation decisions are uncertain, and because growers have leeway over the timing of cropping and fumigation decisions, there is an option value to waiting which requires a dynamic model (Dixit and Pindyck, 1994). Third, Verticillium dahliae takes time to build up in the soil, and once present, persists for many years.

There are several advantages to using a dynamic structural model to model grower crop and fumigation decisions. First, unlike reduced-form models, a structural approach explicitly models the dynamics of crop and fumigation decisions by incorporating continuation values that explicitly model how expectations about the future affect current decisions.

A second advantage of the structural model is that we are able to estimate the effect of each state variable on the expected payoffs from different crop and fumigation choices, and are therefore able to estimate parameters that have direct economic interpretations. The dynamic model accounts for the continuation value, which is the expected value of the value function next period. With the structural model we are able to estimate parameters in the payoffs from different crop and fumigation choices, since we are able to structurally model how the continuation values relate to the payoffs from the crop and fumigation choices.

A third advantage of our structural model is that we can use the parameter estimates from our structural model to simulate the effects of crop disease on agricultural productivity. In particular, we run counterfactual simulations to analyze the effects of $\mathrm{V}$. wilt on cropfumigation decisions and on grower welfare.

The balance of this paper proceeds as follows. Section 2 provides background on the California lettuce industry, V. wilt, and options to control the disease. Section 3 is a brief review of the relevant literature. Section 4 describes our dynamic structural econometric model. Section 5 describes our data. We present our results in Section 6 and our counterfactual simulations in Section 7. Section 8 concludes.

can also be beneficial to the current crop of strawberries. However, on net, these control options generally require incurring net costs or foregoing profit in the current period. 


\section{Background}

California, a major agricultural producer and global trader, sustains significant economic damage from invasive plant pathogens. Fungi damage a wide variety of California crops, resulting in yield- and quality-related losses, reduced exportability, and increased fungicide expenditures (Palm, 2001).

Measured by value, lettuce ranks in the top ten agricultural commodities produced in California (National Agricultural Statistics Service, 2015). Much of California's lettuce crop is grown in Monterey County, where lettuce production value is $27 \%$ of the county's agricultural production value (Monterey County Agricultural Commissioner, 2015). Approximately ten to fifteen thousand acres are planted to lettuce in Monterey County each season (spring, summer, and fall). Spinach, broccoli, and strawberries are also important crops in the region.

Verticillium dahliae is a soil borne fungus that causes lettuce to be afflicted with V. wilt. No effective treatment exists once plants are infected by the fungus (Xiao and Subbarao, 1998; Fradin and Thomma, 2006). The fungus can survive in the soil for fourteen years as microsclerotia, which are resting structures that are produced as the pathogen colonizes a plant. This system allows the fungus to remain in the soil even without a host plant. When a susceptible host is planted, microsclerotia attack through the roots, enter the water conducting tissue, and interfere with the water uptake and transport through the plant. If the density of microsclerotia in the soil passes a threshold, a disease known as V. wilt occurs.

V. wilt first killed a lettuce (Lactuca sativa L.) crop in California's Parajo Valley in 1995. Prior to 1995, lettuce was believed to be immune. Since then, the disease has spread rapidly through the Salinas Valley, the prime lettuce production region of California. By 2010, more than 150 fields were infected with V. wilt (Atallah, Hayes, and Subbarao, 2011), ${ }^{3}$

\footnotetext{
${ }^{3}$ As not all the fields that were infected by 2010 were known at the time Atallah, Hayes, and Subbarao (2011) was published, the number of fields affected by 2010 fields was actually even higher, numbering over 175 fields (Krishna Subbarao, personal communication, 2013).
} 
amounting to more than 4,000 acres (Krishna Subbarao, personal communication, 2013). Although growers have resisted reporting the extent of the disease since 2010, it is likely that the number of affected acres has increased since then (Krishna Subbarao, personal communication, 2013).

Verticillium dahliae is introduced to the soil in three possible ways. First, V. wilt can be spread locally from field to field by workers or equipment. Local spread is a relatively minor contributor, however, and growers have taken steps to mitigate this issue themselves, for example by cleaning equipment before moving between fields.

Second, V. wilt is introduced to the soil via infested lettuce seeds. However, studies of commercial lettuce seed lots from around the world show that fewer than $18 \%$ tested positive for Verticillium dahliae and, of those, the maximum incidence of infection was less than $5 \%$ (Atallah, Hayes, and Subbarao, 2011). These relatively low levels do not cause V. wilt in lettuce at an epidemic level. Models of the disease suggest that it would be necessary for lettuce seed to have an incidence of infection of at least $5 \%$ and be planted back to back for three to five seasons in order for the disease to appear, with at least five subsequent seasons required for the high disease levels currently seen (Atallah, Hayes, and Subbarao, 2011).

Third, V. wilt is introduced to the soil via infested spinach seeds. Spinach seeds have been shown to be the main source of the disease (du Toit, Derie, and Hernandez-Perez, 2005; Short, D.P.G. et al., 2015); 89\% of spinach seed samples are infected, with an incidence of infected seeds per sample of mean $18.51 \%$ and range $0.3 \%$ to $84.8 \%$ (du Toit, Derie, and Hernandez-Perez, 2005). The precise impact of planting infected spinach seeds on V. wilt of lettuce was recently assessed and proven to be the cause of the disease on lettuce (Short, D.P.G. et al., 2015). The pathogen isolated from infected lettuce plants is genetically identical to the pathogen carried on spinach seeds (Atallah et al., 2010).

Infected spinach seeds carry an average of 200 to 300 microsclerotia per seed (Maruthacha-

\footnotetext{
${ }^{4}$ Krishna Subbarao is a Professor of Plant Pathology and Cooperative Extension Specialist at the University of California at Davis. He has studied V. wilt for many years.
} 
lam et al., 2013). As spinach crops are seeded at up to nine million seeds per hectare for baby leaf spinach, even a small proportion of infected seeds can introduce many microsclerotia (du Toit and Hernandez-Perez, 2005).

One method for controlling $\mathrm{V}$. wilt is to fumigate with methyl bromide. As methyl bromide is an ozone depleting substance, the Montreal Protocol has eliminated methyl bromide use for fumigation of vegetable crops such as lettuce; however, certain crops such as strawberries have received critical-use exemptions through $2016^{5}$ (California Department of Pesticide Regulation, 2010; United States Environmental Protection Agency, 2012b), and the residual effects from strawberry fumigation provide protection for one or two seasons of lettuce before microsclerotia densities rise (Atallah, Hayes, and Subbarao, 2011). The long-term availability of this solution is limited and uncertain.

A second method for controlling V. wilt is to plant broccoli. Broccoli is not susceptible to V. wilt and it also reduces the levels of microsclerotia in the soil (Subbarao and Hubbard, 1996; Subbarao, Hubbard, and Koike, 1999; Shetty et al., 2000). Some growers have experimented with this solution, but relatively low returns from broccoli in the region prevent this option from becoming a widespread solution. Planting all infected acreage to broccoli may also flood the market, driving down broccoli prices.

A third method for controlling $\mathrm{V}$. wilt is to not plant spinach, since spinach seeds are the vector of pathogen introduction (du Toit, Derie, and Hernandez-Perez, 2005). Growers who use this third control method of not planting spinach must forgo any relative profits they may have received if they planted spinach instead of another crop.

In addition to the control measures that the grower can take, $\mathrm{V}$. wilt can also be prevented or controlled by a spinach seed company through testing and cleaning the spinach

\footnotetext{
${ }^{5}$ Critical-use exemption requests through 2014 specify that up to one third of the California strawberry crop will be fumigated with methyl bromide, but actual use was much lower. The remainder of the crop is treated with alternatives such as chloropicrin or 1,3-Dichloropropene (1,3-D) (United States Environmental Protection Agency, 2012a). However, these alternatives (unless combined with methyl bromide) tend to be less effective for V. wilt (Atallah, Hayes, and Subbarao, 2011). Field trials of other chemical fumigants either have not been widely used due to township caps or are not yet registered and approved.
} 
seeds. Testing or cleaning seeds is an important option for preventing Verticillium dahliae from being introduced into a field, but can be uncertain and potentially costly. Although Verticillium dahliae cannot be completely eliminated by seed cleaning, incidence levels in spinach seed can be significantly reduced (du Toit and Hernandez-Perez, 2005). Very recent developments in testing procedures suggest that testing spinach seed for Verticillium dahliae might soon be feasible on a commercial basis. Moreover, a very recent innovation speeds up testing spinach seeds. Previously, testing for Verticillium dahliae in spinach seeds took approximately two weeks and could not accurately distinguish between pathogenic and nonpathogenic species (Duressa et al., 2012). This new method takes only one day to complete, is highly sensitive (as it is able to detect one infected seed out of 100), and can distinguish among species (Duressa et al., 2012).

V. wilt can also be controlled by restricting the imports of spinach seeds infested with Verticillium dahliae, but doing so would have trade implications. Currently, the United States has no phytosanitary restrictions on spinach seed imports, but Mexico prohibits the importation of seeds if more than $10 \%$ are infected (IPC, 2003).

V. wilt can therefore be prevented or controlled by the grower by fumigating with methyl bromide, planting broccoli, or not planting spinach. These control options require long-term investment for future gain. V. wilt can also be prevented or controlled by the spinach seed company by testing and cleaning the spinach seeds. However, seed companies are unwilling to test or clean spinach seeds, as they are not affected by this disease.

\section{Literature Review}

The first strand of literature to which our paper relates is on the economics of pest management (Hueth and Regev, 1974; Carlson and Main, 1976; Wu, 2001; Noailly, 2008; McKee et al., 2009), which focuses on pests for which treatment is available after crops are affected. In contrast, V. wilt cannot be treated once crops are affected. Existing work on crop disease, 
such as Johansson et al. (2006) and Gomez, Nunez, and Onal (2009) on soybean rust, and Atallah et al. (2015) on grapevine leafroll disease, focuses on spatial issues regarding the spread of the disease. In contrast, V. wilt has only a limited geographic impact, and thus dynamic considerations are more important than spatial ones for $\mathrm{V}$. wilt.

A second strand of literature to which our paper relates is on dynamic models in agricultural management. As Verticillium dahliae persists in the soil for many years, a static model such as that proposed by Moffitt, Hall, and Osteen (1984) will not properly account for the future benefits of reducing microsclerotia in the soil. The dynamics of V. wilt more closely fit the seed bank management model by Wu (2001).

Dynamic models have been used in agricultural management to analyze many problems. Weisensel and van Kooten (1990) use a dynamic model of growers' choices to plant wheat, or to use tillage fallow versus chemicals to store moisture. In a related paper, van Kooten, Weisensel, and Chinthammit (1990) use a dynamic model that explicitly includes soil quality in the grower's utility function and the trade-off between soil quality (which may decline due to erosion) and net returns.

Our paper builds on the literature on dynamic structural econometric modeling. Rust's (1987; 1988) seminal papers develop a dynamic structural econometric model using nested fixed point maximum likelihood estimation. This model has been adapted for many applications, including bus engine replacement (Rust, 1987), nuclear power plant shutdown (Rothwell and Rust, 1997), water management (Timmins, 2002), agriculture (De Pinto and Nelson, 2009; Scott, 2013), air conditioner purchases (Rapson, 2014), wind turbine shutdowns and upgrades (Lin Lawell, 2017), and copper mining decisions (Aguirregabiria and Luengo, 2016). Carroll et al. (2017a) develop and estimate a dynamic structural model to analyze short- versus long-term decision-making for disease control. Carroll et al. (2017b) develop and estimate a dynamic structural model to analyze the supply chain externality between growers and spinach seed companies in controlling V. wilt. 


\section{Dynamic Structural Econometric Model}

To analyze the effects of $\mathrm{V}$. wilt on, we develop and estimate a single-agent dynamic structural econometric model using the econometric methods developed by Rust (1987). Each month $t$, each grower $i$ chooses an action $d_{i t} \in D$. The possible actions for each grower for each month include one of five crops (resistant, susceptible (other than lettuce), lettuce, spinach, and broccoli), combined with the choice to fumigate with methyl bromide. To focus on the crops most relevant to this problem, we group the crops resistant to $\mathrm{V}$. wilt together and the crops (other than lettuce) susceptible to V. wilt together. Lettuce, spinach, and broccoli are included separately as these crops are most relevant to V. wilt. Susceptible crops include strawberries, artichoke, and cabbage. Resistant crops include cauliflower and celery.

Although the raw data are observations on the day and time any fumigant is applied on a field, we aggregate to monthly observations. Growers are generally only making one crop-fumigation decision each season. The length of the season varies among crops, and can be as short as one month for spinach and more than a year for strawberries. For this reason, we choose a month as the time period for each crop-fumigation decision. To cover the case of multi-month seasons, we include a dummy variable for whether the grower continues with the same crop chosen in the previous month. Moreover, because not all crops are harvested in all months, we also include dummy variables for each crop-month indicating whether a particular month is a harvest month for a particular crop. For example, although Monterey County grows crops during a large portion of the year, few crops are harvested in the winter months.

To estimate growers' losses from V. wilt, it would be ideal to observe actual prices, quantities, costs, and level of microsclerotia for both growers facing losses from V. wilt and those who are not. In theory, profit maximizing growers make optimal planting and fumigating decisions factoring in planting and input costs, as well as the costs of microsclerotia building up in the soil over time and potentially impacting future crops. Unfortunately, data 
on growers' actual price, quantity, costs, and level of microsclerotia are not available. ${ }^{6}$

We account for the important factors in a grower's profit maximizing decision by including in the payoff function state variables that affect revenue; state variables that affect costs; state variables that affect both revenue and costs; and state variables that affect either revenue or cost by affecting the microsclerotia and the spread of $\mathrm{V}$. wilt. The different state variables we include may have effects on price, yield, input costs, or microsclerotia levels. Costs are accounted for by the crop-fumigation dummies and the constant in our model, and we allow these costs to differ between the early and later periods of our data set. The largest cost difference among crops is due to fumigation, so we include a dummy for methyl bromide fumigation to account for the net costs of fumigation and to absorb cost differences among crops.

The per-period payoff to a grower from choosing action $d_{i t}$ at time $t$ depends on the values of the state variables $\mathbf{s}_{\mathbf{i t}}$ at time $t$ as well as the choice-specific shock $\epsilon_{i t}\left(d_{i t}\right)$ at time $t$. The state variables $\mathbf{s}_{\mathbf{i t}}$ at time $t$ include crop prices for each crop $\left(\right.$ price $\left._{i t}\left(d_{i t}\right)\right)$, dummy variables for each crop indicating whether this month is a harvest month for that crop (harvest month dummy ${ }_{i t}\left(d_{i t}\right)$ ), dummy variables for each crop indicating whether that crop is the same as the crop chosen in the previous month (last crop dummy $y_{i t}\left(d_{i t}\right)$ ), a variable measuring whether and how much the methyl bromide control option was used in the past (methyl bromide history $y_{i t}$ ), and a variable measuring whether and how much the broccoli control option was used in the past (broccoli history $y_{i t}$ ).

There is a choice-specific shock $\epsilon_{i t}\left(d_{i t}\right)$ associated with each possible action $d_{i t} \in D$. Let $\epsilon_{i t}$ denote the vector of choice-specific shocks faced by grower $i$ at time $t: \epsilon_{i t} \equiv\left\{\epsilon_{i t}\left(d_{i t}\right) \mid d_{i t} \in\right.$ $D\}$. The vector of choice-specific shocks $\epsilon_{i t}$ is observed by grower $i$ at time $t$, before grower $i$ makes his time- $t$ action choice, but is never observed by the econometrician.

The per-period payoff to a grower from choosing action $d_{i t}$ at time $t$ is given by: ${ }^{7}$

\footnotetext{
${ }^{6}$ The University of California at Davis "Cost and Return Studies" have a limited number of estimates for the revenue and costs, but estimates are not available for all the crops and years in our model.

${ }^{7}$ Because the model requires discrete data, we bin the action and state variables. This means that there
} 


$$
U\left(d_{i t}, \mathbf{s}_{\mathbf{i t}}, \epsilon_{i t}, \theta\right)=\pi\left(d_{i t}, \mathbf{s}_{\mathbf{i t}}, \theta\right)+\epsilon_{i t}\left(d_{i t}\right),
$$

where the deterministic component $\pi(\cdot)$ of the per-period payoff is given by:

$$
\begin{aligned}
& \pi\left(d_{i t}, \mathbf{s}_{\mathbf{i t}}, \theta\right)=\theta_{1} \cdot \text { spinach dummy } \\
&+\theta_{2} \cdot \text { methyl bromide dummy }_{i t} \\
&+\theta_{3} \cdot \text { broccoli dummy }_{i t} \\
&+\theta_{4} \cdot\left(\text { lettuce dummy }_{i t} * \text { methyl bromide history }_{i t}\right) \\
&+\theta_{5} \cdot\left(\text { lettuce dummy }_{i t} * \text { broccoli history }_{i t}\right) \\
&+\theta_{6} \cdot\left(\text { spinach dummy }_{i t} * \text { methyl bromide history }_{i t}\right) \\
&+\theta_{7} \cdot\left(\text { spinach dummy }_{i t} * \text { broccoli history }_{i t}\right) \\
&+\theta_{8} \cdot \text { lettuce dummy }_{i t} \\
&+\theta_{9} \cdot\left(\text { price }_{i t}\left(d_{i t}\right)^{*} \operatorname{harvest~month~dummy~}_{i t}\left(d_{i t}\right)\right) \\
&+\theta_{10} \cdot \text { last crop dummy }_{i t}\left(d_{i t}\right) \\
&+\theta_{11},
\end{aligned}
$$

where spinach dummy ${ }_{i t}$, methyl bromide dummy $y_{i t}$, broccoli dummy ${ }_{i t}$, and lettuce dummy $y_{i t}$ are among the possible actions $d_{i t} \in D$.

Spinach will tend to increase microsclerotia, thus decreasing the quantity harvested, increasing microsclerotia costs, and potentially increasing input costs as growers need to fumigate more. The coefficient $\theta_{1}$ on the spinach dummy captures the effects of spinach on payoffs that are not internalized in the spinach price.

Especially in more recent years, methyl bromide fumigation is very expensive and are no meaningful units associated with the variables, payoffs, or value functions; and the payoff and value functions described in the model do not explicitly measure revenue or profit. However, the payoff function does include action and state variables that affect revenue (such as price); costs (such as the methyl bromide dummy); both revenue and costs; and either revenue and/or costs through their effect on microsclerotia and the spread of $\mathrm{V}$. wilt. 
raises input costs dramatically. Fumigation is the largest cost difference among crops. Thus, methyl bromide fumigation is a control option that requires incurring costs or forgoing profit in the current period for future benefit. The coefficient $\theta_{2}$ on the dummy for methyl bromide fumigation accounts for the costs of fumigation and absorbs the cost differences among crops. $^{8}$

Broccoli is not highly profitable, but may yield future benefits for lettuce growers. Thus, planting broccoli is a control option that requires incurring costs or forgoing profit in the current period for future benefit. The coefficient $\theta_{3}$ on the broccoli dummy captures the effects of broccoli on payoffs that are not internalized in the broccoli price.

Since the control options require incurring costs or forgoing profit in the current period for future benefit, previous use of control options may affect current payoffs. We therefore include variables indicating the fumigation history with methyl bromide within the last twelve months and the broccoli history within the last twelve months. We expect methyl bromide fumigation history and broccoli history to be closely linked to the presence of microsclerotia in a field. Methyl bromide fumigation history and broccoli history will tend to decrease microsclerotia levels in the soil, leading to increased harvest for susceptible crops, lower microsclerotia costs, and lower input costs.

We interact the variables measuring previous use of control options with a dummy variable for lettuce being planted in the current period because lettuce is the primary susceptible crop. Methyl bromide fumigation history interacted with planting lettuce today would have a positive coefficient $\theta_{4}$ if having fumigated with methyl bromide is an effective control option. Similarly, broccoli history interacted with planting lettuce today would have a positive coefficient $\theta_{5}$ if having planted broccoli is an effective control option. These two parameters therefore enable us to assess the effectiveness of these two respective control

\footnotetext{
${ }^{8}$ In addition to being an investment in protecting potential future lettuce crops from V. wilt, methyl bromide can also be beneficial to the current crop of strawberries. However, on net, methyl bromide fumigation generally requires incurring net costs or foregoing profit in the current period. A negative sign on the coefficient on the dummy for methyl bromide fumigation would indicate a net cost to methyl bromide fumigation.
} 
options.

We also interact the methyl bromide history and broccoli history variables with the dummy variable for spinach being planted in the current period, to capture whether the undesirability of spinach is mitigated by having methyl bromide history and/or broccoli history.

Growers continue to plant lettuce even though it is susceptible, and the coefficient $\theta_{8}$ on the lettuce dummy captures any additional benefit of lettuce beyond its price.

Growers base decisions in part on the price or gross return they expect to receive for their harvested crops (Scott, 2013). We interact price with a dummy variable that is equal to one during the harvest season for each crop to capture the fact that although a grower may plant the same crop for multiple months, he only receives revenue during the months of the harvest season for that crop. ${ }^{9}$ In particular, the expected gross revenue to harvesting a crop during non-harvest season months (e.g., during the winter) is $0 .{ }^{10}$ Thus, by incorporating the expected gross return in the payoff of function and by modeling the dynamic decisionmaking of growers of when and what to plant, and whether and when to fumigate, our model accounts for the biological reality of how long a crop needs to be in the ground, because a profit maximizing grower is unlikely to pull out the crop before it is ready to harvest (and therefore before he would receive the expected return), barring problems such as V. wilt or

\footnotetext{
${ }^{9}$ On average, the length of the harvest season is less than 2 months in our data set, and equal to about 1.5 months on average for most crops. The exception are susceptible crops, which include strawberries, and which have an average harvest season length of 2.59 months. In the case of strawberries, however, strawberries are an ongoing harvest crop and therefore the more months in the harvest season it is grown, the more product can be harvested, so it is reasonable to assume that a grower may receive revenue each harvest month during which strawberries are grown. We choose not to model the grower as only receiving the revenue for his crop the first month of the harvest season, as this would not explain why growers may plant the same crop for multiple months in the harvest season. Staying in the harvest season longer sometimes yields higher revenue because it enables the grower to harvest more product or replant the crop for more harvest, both of which are better captured by having the grower receive more revenue if he stays in the harvest season longer. For similar reasons, we choose not to model the grower as only receiving the revenue for his crop the last month of the harvest season. As seen in Carroll et al. (2017a), we find that the results are robust to whether we divide the marketing year average price for each crop by its average harvest season length, and therefore to whether we assume growers who plant the same crop for multiple months receive more revenue than those who plant that crop for only one month.

${ }^{10}$ The costs of inputs are included in the constant, which we expect to be negative.
} 
other issues that meant that crop was unhealthy.

The last crop dummy variable is equal to one if the crop chosen this month is the same as the crop planted in the previous month. The last crop dummy captures both the requirement to grow a particular crop over multiple months, as well as any tendency for a grower to choose to replant the same crop over and over again, perhaps harvest after harvest.

The value function for a long-term grower, which gives the present discounted value of the grower's entire stream of per-period payoffs at the optimum, is given by the following Bellman equation:

$$
V(\mathbf{s}, \epsilon, \theta)=\max _{d \in D}\left(\pi(d, \mathbf{s}, \theta)+\epsilon(d)+\beta \int V\left(\mathbf{s}^{\prime}, \epsilon^{\prime} ; \theta\right) d \operatorname{Pr}\left(\mathbf{s}^{\prime}, \epsilon^{\prime} \mid \mathbf{s}, \epsilon, d, \theta\right)\right),
$$

where $\beta$ is the discount factor. We set our monthly discount factor to $\beta=0.999$.

To estimate the unknown parameters $\theta=\left(\theta_{1}, \ldots, \theta_{11}\right)$, we use a nested fixed point maximum likelihood estimation technique developed by Rust $(1987,1988)$. We assume the observed choices are the result of the optimal decision rule $d_{t}=\gamma\left(\mathbf{s}_{t}, \epsilon_{t}\right)$ that solves the Bellman equation.

We assume the state variables evolve as a first-order Markov process, with a transition density given by $\operatorname{Pr}\left(\mathbf{s}_{t+1}, \epsilon_{t+1} \mid \mathbf{s}_{t}, d_{t}, \epsilon_{t}, \theta\right)$. Since the price variable we use is the annual county average, we assume that the choice of any one grower would not have a large enough effect to influence prices and therefore that the distribution of price next period does not depend on any single grower's decisions this period; we therefore model crop prices as evolving exogenously. The endogenous state variables (methyl bromide fumigation history, broccoli history, and last crop dummy) evolve deterministically as a function of this period's action.

We assume that the state variables and the choice-specific shocks $\epsilon_{i t}$ are conditionally independent and that the choice-specific shocks $\epsilon_{i t}$ are distributed multivariate extreme value. Under these assumptions, the value function for a long-term grower given in Equation (2) can be rewritten as: 


$$
V(\mathbf{s}, \epsilon, \theta)=\max _{d \in D(\mathbf{s})}\left(\pi(d, \mathbf{s}, \theta)+\epsilon(d)+\beta V^{c}(\mathbf{s}, d, \theta)\right)
$$

where $V^{c}(\cdot)$ is the continuation value, which is the expected value of the value function next period conditional on the state variables and action this period:

$$
V^{c}(\mathbf{s}, d, \theta)=\int V\left(\mathbf{s}^{\prime}, \epsilon^{\prime} ; \theta\right) d \operatorname{Pr}\left(\mathbf{s}^{\prime}, \epsilon^{\prime} \mid \mathbf{s}, \epsilon, d, \theta\right)
$$

The choice probability for a long-term grower is given by:

$$
\operatorname{Pr}(d \mid \mathbf{s}, \theta)=\frac{\exp \left(\pi(d, \mathbf{s}, \theta)+\beta V^{c}(\mathbf{s}, d, \theta)\right)}{\sum_{\tilde{d} \in D(\mathbf{s})} \exp \left(\pi(\tilde{d}, \mathbf{s}, \theta)+\beta V^{c}(\mathbf{s}, \tilde{d}, \theta)\right)}
$$

After obtaining the model predictions for the choice probabilities as functions of the state variables and the unknown parameters $\theta$, the parameters $\theta$ can then be estimated using maximum likelihood. The likelihood function is a function of the choice probabilities, and therefore a function of the continuation value $V^{c}(\cdot)$. Solving for the parameters $\theta$ via maximum likelihood thus requires an inner fixed point algorithm to compute the continuation value $V^{c}(\cdot)$ as rapidly as possible and an outer optimization algorithm to find the maximizing value of the parameters $\theta$, i.e., a fixed point calculation is nested within a maximum likelihood estimation (MLE). From Blackwell's Theorem, the fixed point is unique.

Identification of the parameters $\theta$ comes from the differences between per-period payoffs across different action choices, which in infinite horizon dynamic discrete choice models are identified when the discount factor $\beta$ and the distribution of the choice-specific shocks $\epsilon_{i t}$ are fixed (Abbring, 2010; Magnac and Thesmar, 2002; Rust, 1994). In particular, the parameters in our model are identified because each term in the deterministic component $\pi(\cdot)$ of the perperiod payoff given in Equation (1) depends on the action $d_{i t}$ being taken at time $t$, and therefore varies based on the action taken; as a consequence, the parameters do not cancel out in the differences between per-period payoffs across different action choices and are therefore 
identified. For example, the coefficient $\theta_{1}$ on the spinach dummy is identified in the difference between the per-period payoff from choosing to plant spinach and the per-period payoff from any action choice $d_{i t}$ that does not involve planting spinach. ${ }^{11}$

Standard errors are formed by a nonparametric bootstrap. Fields are randomly drawn from the data set with replacement to generate 100 independent panels each with the same number of fields as in the original data set. The structural model is run on each of the new panels. The standard errors are then formed by taking the standard deviation of the parameter estimates from each of the panels.

\section{Data}

We use Pesticide Use Reporting (PUR) data from the California Department of Pesticide Regulation. ${ }^{12}$ Our data set is composed of all fields in Monterey County on which any regulated pesticide was applied in the years 1993 to 2011, inclusive. ${ }^{13}$ Additional data on prices, yields, and acreage come from the Monterey Agricultural Commissioner's Office. We collapse the data set into monthly observations.

We group the crops into six categories: susceptible (which includes artichoke, strawberries, and cabbage, but excludes lettuce which we represent separately), resistant (cauliflower and celery), lettuce, spinach, broccoli, and other. ${ }^{14}$ From these, we form nine action choices: susceptible, susceptible with recent fumigation, resistant, broccoli, broccoli with recent fumigation, lettuce, lettuce with recent fumigation, spinach, and other. ${ }^{15}$

\footnotetext{
${ }^{11}$ To identify the constant $\theta_{11}$, we normalize the deterministic component $\pi(\cdot)$ of the per-period payoff from choosing "other" to 0.

${ }^{12}$ For more information see: http://www.cdpr.ca.gov/docs/pur/purmain.htm.

${ }^{13}$ We use the field identifier as as well as the section, township, and range data from the PUR data set to match fields across time. We delete a small number of observations that are non-agricultural uses (golf courses, freeway sidings, etc.).

${ }^{14}$ To make the model manageable, we include only the most common crops in Monterey County and those that are most often grown in rotation with lettuce. The crops explicitly included in our model account for nearly $90 \%$ of the observations. We account for the many rarely planted crops by including an "other" option, which includes various herbs, berries, nursery products, nuts, wine grapes, livestock, and many others.

${ }^{15}$ The data contain the crop planted in each field for each recorded pesticide application. Although the
} 
For control options, we use recent histories for broccoli and methyl bromide because their effects on microsclerotia are relatively short-lived. Microsclerotia levels rebound within one to two seasons, or approximately one year. Thus, broccoli history is the number of months broccoli was planted in the last 12 months, and methyl bromide history is the number of months methyl bromide was used in the last 12 months.

The vast majority of fields (94\% of observations) in our data set have only one grower over the entire time period. Of these, we analyze those long-term growers who appear in the data on from 1994 to 2010, and we model their decision-making as an infinite horizon problem. This data set on long-term growers consists of 615 fields, each over seventeen years.

We use a marketing year average price for each crop ${ }^{16}$ to represent growers' expectations about prices for each year. The marketing year average price is in units of dollars per acre, and therefore measures revenue per acre and incorporates yield. ${ }^{17}$ Using the current year's marketing year average price assumes that growers have rational expectations about what focus of our research is on methyl bromide, the other pesticides provide observations regarding which crops are in the ground at which times. Due to the nature of the data, sometimes we do not observe the entire production cycle of a crop. For example, strawberries are often in the ground for a year or more; however, if there is no registered pesticide applied in one of those months, a gap in the production cycle may appear in our data. We account for this issue in several ways. As long as the missing data are missing for exogenous reasons, missing data will not bias the results. Since there are no pesticide treatments for V. wilt once crops are in the ground, we have reason to believe that missing months mid-production cycle due to no pesticide application in that month are exogenous to the impact of $\mathrm{V}$. wilt on crop and methyl bromide fumigation choice. We compared the distribution of these months between short-term and long-term growers and find that they are similar distributions. Finally, in the simulations, we simulate all months in the time period, but only count grower-months that are present in the actual data when calculating welfare and other statistics for comparison purposes.

${ }^{16}$ For lettuce, we use a weighted average of the prices for head and leaf lettuce. In the early years of the data set, romaine and other types of lettuce were not broken out separately, so gross revenue numbers vary based on this reporting, but do not affect the discretized value of the price.

${ }^{17}$ We look at gross revenue rather than net revenue due to data limitations. Costs are captured by our crop-fumigation dummies and our constant. Estimating net revenue did not improve the overall model, and cost differences among crops are mainly driven by methyl bromide fumigation, which is explicitly included in the model, and/or the difference between strawberry costs compared to other crops. Strawberry costs are generally an order of magnitude higher than for the vegetable crops, in part due to fumigation cost according to Richard Smith, Farm Advisor for Vegetable Crop Production \& Weed Science with the University of California Cooperative Extension in Monterey County. We also attempted to incorporate this effect by including dummy variables for the different crop choices and fumigation, with resistant crops as the baseline. Unsurprisingly, the susceptible dummy variables (which includes strawberries) was collinear with the methyl bromide fumigation variable; we therefore do not include the susceptible crop dummy variable in our model. We expect the crop-fumigation dummies to at least partially capture the cost differences among the different crops. 
the average marketing year price will be that year. ${ }^{18}$ The Monterey County Agricultural Commissioner's Office publishes annual crop reports including prices, yields harvest, and acreages for major crops in the county. Monterey County is a major producer of many of the crops included in our model. For most crops, these prices are highly correlated with California-wide price data published by the National Agricultural Statistics Service. We discretize the marketing year average price into 6 bins; the marketing year average price bins are shown in Figure 1.

We combine the marketing year average price data with data on the timing of harvests for various crops in Monterey. For each crop, the harvest month dummy variable for that crop is equal to one in months during which that crop may be harvested, and zero in months during which that crop is not harvested (i.e., winter months for most crops). ${ }^{19}$ For all crops, we have observations during the winter months, including crops that have just been planted and are not yet ready for harvest, and crops such as strawberries that overwinter for harvest in the coming year.

Summary statistics for the state variables for long-term growers are in Table 1. The mean discretized price for broccoli is relatively low, affirming that broccoli is a low-return crop. Spinach is a relatively small portion of the acreage grown in Monterey County, approximately a tenth of the size of the acreage planted to lettuce according to the most recent Monterey County Crop Report.

Figure 2 plots the actual fraction of grower-months in each action type for the longterm growers. As seen in Figure 2, lettuce accounts for over $60 \%$ of the grower-months for these long-term growers. Figure 3 plots the actual fraction of grower-months in each action by month of year. The actual fraction of grower-months in each action varies by the month

\footnotetext{
${ }^{18}$ Instead of rational expectations about price, another possible assumption is that growers' best guess for this year's price is last year's price. The results are robust to whether we use lagged prices rather than current prices (Carroll et al., 2017a).

${ }^{19}$ There is a separate harvest month dummy variable for each crop-month. These data come from Richard Smith, Farm Advisor for Vegetable Crop Production \& Weed Science with the University of California Cooperative Extension in Monterey County.
} 
of the year, with lettuce predominant in the spring and summer months, and other and susceptible crops having the highest proportion in the winter months. Figure 4 plots the actual fraction of grower-months in each action type over the years. The proportions are relatively constant across years.

\section{Results}

The results for long-term growers are presented in Table 2. We run our model on 3 different time periods: the entire time period of our data set ('all'), the early half of the data prior to 2001 ('early'), and the later half of the data from 2001 to 2011 ('late'). We report our estimates for the parameters in the per-period payoff function in Equation (1). The payoffs do not have units because price is discretized and therefore no longer in dollars. Since we do not have units for payoffs, we can compare only relative payoffs and welfare.

According to the results, the coefficient on the spinach dummy is significant and negative, suggesting that planting spinach is undesirable for reasons that are not fully captured by its price. ${ }^{20}$ This coefficient provides evidence that $\mathrm{V}$. wilt is a problem, since it is likely due to the fact that spinach is associated with $\mathrm{V}$. wilt that spinach is undesirable. ${ }^{21}$

The coefficient on methyl bromide in the current period is significant and negative, which means there is a cost to methyl bromide that may yield future benefit to either the current crop or a future crop. The coefficient is more negative in the later half of the data, likely because the Montreal Protocol started to limit the legal availability of methyl bromide during this period (California Department of Pesticide Regulation, 2010; United

\footnotetext{
${ }^{20}$ Because price is the discretized marketing average price of spinach per acre, the price measures revenue per acre, and therefore incorporates yield as well. Thus, the significant negative coefficient on the spinach dummy suggests that spinach is not desirable to plant for reasons that are not fully captured by its price, yield, or revenue per acre.

${ }^{21}$ One may worry that the negative coefficient on the spinach dummy is possibly also consistent with a problem in modeling where the other crops with longer crop cycles would potentially be more appealing than spinach. However, even when returns are divided by the length of season, the returns to spinach versus other crops still follow the same order. This result suggests that the season length is not the driving factor behind this coefficient. We confirm in Carroll et al. (2017a) that the significant negative coefficient on the spinach dummy is robust to whether we divide returns by season length.
} 
States Environmental Protection Agency, 2012b), and also because there is more demand for methyl bromide in the later half of the data set when V. wilt became more of a problem, resulting in a higher price for using methyl bromide.

The broccoli dummy coefficient is negative, but not significant, suggesting that planting broccoli is not as desirable as planting lettuce (since the lettuce dummy has a significant positive coefficient) and requires foregoing current benefits (or incurring current costs) for future gain.

The coefficient on the interaction term between lettuce and methyl bromide history is significant and positive in the later half of the time period, suggesting that methyl bromide is an effective control option in the later period. Similarly, the coefficient on the interaction term between lettuce and broccoli history is significant and positive, which suggests that planting broccoli is also an effective control option.

Although the coefficient on the spinach dummy and methyl bromide history interaction term is not significant, the point estimate is positive and smaller in magnitude than the spinach dummy coefficient, suggesting that the undesirability of spinach is mitigated by having methyl bromide history. In addition to the significant positive coefficient on the lettuce and methyl bromide interaction in the later period, this further suggests that methyl bromide is an effective control option in the later period.

Similarly, although the coefficient on the spinach dummy and broccoli history interaction term is not significant, the point estimate is positive and smaller in magnitude than the spinach dummy, also suggesting that the undesirability of spinach is mitigated by broccoli history. In addition to the significant positive coefficient on the lettuce and broccoli history interaction, this further suggests that planting broccoli is an effective control option.

The lettuce dummy has a significant positive coefficient, which means that owners derive benefits from planting lettuce beyond its price, such as meeting shipper contract requirements. ${ }^{22}$ Thus, it is desirable for growers to control V. wilt, since they benefit from

\footnotetext{
${ }^{22}$ In the model, returns are estimated at the county level, so although contracts can and do specify prices,
} 
planting lettuce.

The coefficient on price at the time of harvest is negative. At first blush this may appear counterintuitive, as economic theory predicts that price will have a positive effect on return. After looking further into the data, however, the reason for this result becomes more clear. Strawberries have a much higher revenue per acre than any of the vegetable crops included in this data set, on the order of $\$ 70,000$ for strawberries versus $\$ 20,000$ or less for some vegetable crops. Most growers concentrate on either strawberry crops or vegetable crops, so there are very few cases in the data of growers switching to strawberries from vegetable crops, even though that behavior is what one would expect based on price alone. When strawberries are removed as an action choice in the analysis, the coefficient for price is then positive. In addition, some strawberry growers are switching to contracts in which the price plays very little role in determining their profit. They are paid a baseline amount for growing the crop and may make more money in a particularly good year, but do not bear the downside risk in a poor year.

The negative coefficient on price at the time of harvest therefore suggests that there may be something partially driving growers' decision-making that is not observable. For example, growers may have connections and contracts that tie them to certain crops that we cannot observe. They may have expertise or risk profiles that better suit certain crops. Perhaps some growers consider themselves vegetable growers and the cost of switching to strawberries is too high. Uncertainty related to the future of methyl bromide and its lack of suitable replacements for treating $\mathrm{V}$. wilt could also play a role. Unobservable factors that may make growers less likely to switch crops are at least partially captured in our model by the last crop dummy. We hope to explore these issues further in future work.

The coefficient on the last crop dummy is significant and positive, which suggests that growers are committed to previous crops, which is also consistent with the hypothesis that growers do not switch crops often and therefore are less responsive to price.

we expect the return used in the model to be exogenous to contracting decisions. 
The total average effects of the variables that appear in more than one term of the per-period payoff function are reported at the bottom of Table 2. The spinach dummy has a total average effect that is significant and negative on net, which provides evidence that $\mathrm{V}$. wilt is a problem, even if the undesirability of spinach is mitigated by having methyl bromide history and/or broccoli history.

The lettuce dummy has a significant and positive total average effect, which means that owners derive benefits from planting lettuce beyond its price, and that the benefits of lettuce are enhanced in the presence of control options such as methyl bromide history and/or broccoli history.

Methyl bromide history has a positive total average effect that is significant in the later half of the time period, suggesting that methyl bromide is an effective control option in the later period. Similarly, broccoli history has a significant and positive total average effect, suggesting that planting broccoli is an effective control option.

In using a marketing year average price for each crop to represent growers' expectations about prices for each year, we assume that growers have rational expectations about the price. Instead of rational expectations about price, another possible assumption is that growers' best guess for this year's price is last year's price. The results are robust to whether we use lagged prices rather than current prices (Carroll et al., 2017a).

We choose not to model the grower as only receiving the revenue for his crop the first month of the harvest season, as this would not explain why growers may plant the same crop for multiple months in the harvest season. Staying in the harvest season longer sometimes yields higher revenue because it enables the grower to harvest more product or replant the crop for more harvest, both of which are better captured by having the grower receive more revenue if he stays in the harvest season longer. For similar reasons, we choose not to model the grower as only receiving the revenue for his crop the last month of the harvest season. As seen in Carroll et al. (2017a), we find that the results are robust to whether we divide the marketing year average price for each crop by its average harvest season length, and 
therefore to whether we assume growers who plant the same crop for multiple months in a harvest season receive more revenue than those who plant that crop for only one month in the harvest season.

We calculate the normalized average grower welfare per grower per month for the entire time period ('all'), the early time period ('early'), and the later time period ('late'). The welfare is calculated as the present discounted value of the entire stream of payoffs to growers evaluated at the parameter values, summed over all growers in the relevant data set, then divided by the number of grower-months in the relevant data set. The average grower welfare per grower per month is then normalized so that the average welfare per grower per month over the entire time period ('all') is 100 .

The standard errors for the welfare values are calculated using the parameter estimates from each of 100 bootstrap samples. For each of the 100 bootstrap samples, we calculate the average welfare per grower per month using the parameter estimates from that bootstrap sample, and normalize it. The standard error of the normalized welfare is the standard deviation of the normalized welfare over all 100 bootstrap samples.

The welfare results are presented in Table 3. According to the welfare results, average grower welfare per grower-month is higher in the earlier time period than in the later time period, perhaps because $\mathrm{V}$. wilt became more of a problem in the later time period.

\section{Simulations}

We use the estimated parameters from our dynamic structural model to simulate the effects of crop disease on agricultural productivity. In particular, we use counterfactual simulations to analyze the effects of $\mathrm{V}$. wilt on crop-fumigation decisions and on grower welfare.

The severity of the crop disease is measured by the coefficient $\theta_{1}$ on the spinach dummy in the grower's per-period payoff function. The spinach dummy coefficient captures the effects of spinach on payoffs that are not internalized in spinach price. The more negative 
the spinach dummy coefficient $\theta_{1}$, the more severe the disease.

To analyze the effects of crop disease on agricultural productivity, we use the estimated parameters from our dynamic structural model in Section 6 to simulate how different values of the spinach dummy coefficient would affect the choices and payoffs of growers. According to the results of the dynamic structural model for growers in Table 2 , the coefficient $\theta_{1}$ on the spinach dummy when we use data over the entire time period ('all') is -1.1311 .

We consider a set of twenty-one evenly spaced values of the spinach dummy coefficient $\theta_{1}$ between -2.00 and 0.00 . A spinach dummy coefficient $\theta_{1}$ of -2.00 represents a scenario in which V. wilt is even more severe than it currently is, and therefore one in which spinach seeds have an even greater negative effect on grower payoffs than they currently do. A spinach dummy coefficient $\theta_{1}$ equal to zero represents a scenario in which $\mathrm{V}$. wilt is no longer an economically damaging disease, and therefore one in which the effect of spinach on grower payoffs (aside from price effects) is neutral and not economically significant.

For each possible value of the spinach dummy coefficient $\theta_{1}$, we run 100 simulations of the choices and payoffs that would arise if the spinach dummy coefficient were equal that values. For each of the 100 simulations, we calculate the average grower welfare per month, which is the total welfare divided by the number of grower-months. Then, for each possible value of the spinach dummy coefficient, we average the grower welfare per month over the 100 simulations using that value of the spinach dummy coefficient. We then calculate the average benefits to the grower from mitigating the disease taking the average grower welfare per month at each value of the spinach dummy coefficient, and then subtracting the average grower welfare per month when the spinach dummy coefficient $\theta_{1}$ is an extremely severe -2.00. In other words, we normalize the average grower welfare per month when the spinach dummy coefficient $\theta_{1}$ is an extremely severe -2.00 to 0 .

Standard errors are calculated using a nonparametric bootstrap. In particular, we calculate the standard errors of the grower benefits from disease mitigation using the parameter estimates from each of twenty-five bootstrap samples. For each of the twenty-five 
bootstrap samples, we run twenty-five simulations using the parameter estimates from that bootstrap sample. ${ }^{23}$ The standard error of the grower benefits is the standard deviation of the respective statistic over all twenty-five bootstrap samples.

Figure 5 plots the benefits to a grower per month from mitigating the disease, averaged over 100 simulations, as a function of the coefficient $\theta_{1}$ on the spinach dummy achieved. According to our results, the benefits to the growers are the highest when the coefficient on spinach is driven up to zero, which represents the scenario in which $\mathrm{V}$. wilt is no longer an economically damaging disease. As the coefficient on spinach becomes more negative (representing scenarios in which $\mathrm{V}$. wilt is more severe a disease), the benefits to growers decline.

To analyze the effects of mitigating $\mathrm{V}$. wilt on crop-fumigation decisions, we simulate the crop choices of long-term growers when the spinach dummy coefficient $\theta_{1}$ is equal to -1.00 , which represents the scenario in which $\mathrm{V}$. wilt is less severe than it currently is; and when the spinach dummy coefficient $\theta_{1}$ is equal to zero, which represents the scenario in which V. wilt is no longer an economically damaging disease.

Standard errors and 95\% confidence intervals are calculated using a nonparametric bootstrap. In particular, we calculate the standard errors of the simulation statistics (e.g., mean fraction of grower-months in each action) using the parameter estimates from each of twenty-five bootstrap samples. For each of the twenty-five bootstrap samples, we run twentyfive simulations using the parameter estimates from that bootstrap sample. ${ }^{24}$ The standard error of the simulation statistics (e.g., mean fraction of grower-months in each action) is the standard deviation of the respective statistic over all twenty-five bootstrap samples.

\footnotetext{
${ }^{23}$ Constraints on computational time preclude us from running the twenty-five simulations per bootstrap sample for more than twenty-five bootstrap samples per scenario. When we calculated the standard error for welfare for scenario 1 using 100 bootstrap samples instead of twenty-five bootstrap samples, the value of the standard errors were similar using both twenty-five bootstrap samples and 100 bootstrap samples.

${ }^{24}$ Constraints on computational time preclude us from running the twenty-five simulations per bootstrap sample for more than twenty-five bootstrap samples per scenario. When we calculated the standard error for welfare for scenario 1 using 100 bootstrap samples instead of twenty-five bootstrap samples, the value of the standard errors were similar using both twenty-five bootstrap samples and 100 bootstrap samples.
} 
Figures 6-7 simulate growers crop choices when V. wilt is no longer an economically damaging disease $\left(\theta_{1}=0\right)$ and when $\mathrm{V}$. wilt is less severe than it currently is $\left(\theta_{1}=-1.00\right)$, respectively. The fraction of grower-months planted to lettuce is higher under both scenarios than they are in the actual data in Figure 2. Thus, when V. wilt is less severe, growers plant more lettuce, likely because $\mathrm{V}$. wilt then becomes less of a problem.

Figures 8-9 show the fraction of grower-months in each action type by month of year when $\mathrm{V}$. wilt is no longer an economically damaging disease $\left(\theta_{1}=0\right)$ and when $\mathrm{V}$. wilt is less severe than it currently is $\left(\theta_{1}=-1.00\right)$, respectively. Compared to Figure 3, which shows the actual data, the results of the simulations of less severe disease show more grower-months planted to lettuce, especially in the last months of the year when the actual data consists more of susceptible and other crops.

Figures 10-11 show the fraction of grower months in each action type by year when $\mathrm{V}$. wilt is no longer an economically damaging disease $\left(\theta_{1}=0\right)$ and when $\mathrm{V}$. wilt is less severe than it currently is $\left(\theta_{1}=-1.00\right)$, respectively. Compared to Figure 4, which shows the actual data, the results of the simulations of less severe disease show more grower-months planted to lettuce and fewer grower-months planted to other crops. Thus, when the disease is less severe, growers plant more lettuce, likely because V. wilt then becomes less of a problem.

\section{Conclusion}

This paper discusses the effects on agricultural productivity of Verticillium dahliae, a soil borne fungus that is introduced to the soil via infested spinach seeds and that causes lettuce to be afflicted with $\mathrm{V}$. wilt. We use a dynamic structural econometric model of $\mathrm{V}$. wilt management for lettuce crops in Monterey County, California to examine the effects of V. wilt on crop-fumigation decisions and on grower welfare.

According to our results, planting spinach is undesirable for reasons that are not fully captured by its price, which is consistent with the conclusion that V. wilt is a problem. 
Fumigating with methyl bromide and planting broccoli are both effective control options, but involve incurring costs or foregoing profit in the current period for future benefit. We find that average grower welfare per grower-month is higher in the earlier time period than in the later time period, perhaps because $\mathrm{V}$. wilt became more of a problem in the later time period.

According to the results of our counterfactual simulations of the effects of V. wilt on agricultural productivity, the benefits to the growers are the highest when the coefficient on spinach is equal to zero, which represents the scenario in which V. wilt is no longer an economically damaging disease. As the coefficient on spinach becomes more negative (representing scenarios in which $\mathrm{V}$. wilt is more severe a disease), the benefits to growers decline. When the disease is less severe, growers plant more lettuce, likely because V. wilt then becomes less of a problem. Thus, V. wilt has important effects on crop-fumigation decisions, grower welfare, and agricultural productivity.

There are two main externalities that arise due to V. wilt, and that have important implications for agricultural productivity. The first externality is an intertemporal externality. When faced with managing a disease that requires future investment, short- and long-term decision-makers may have different incentives and choose to manage the disease differently. In the case of $\mathrm{V}$. wilt, because the options for controlling $\mathrm{V}$. wilt require longterm investments for future gain, an intertemporal externality arises with short-term growers, who are likely to rent the land for only a short period of time. Renters, therefore, might not make the long-term investments needed to control V. wilt. As a consequence, future renters and the landowner may suffer from decisions of previous renters not to invest in control options. Thus, decisions made by current renters impose an intertemporal externality on future renters and the landowner.

In Carroll et al. (2017a), we analyze the factors that affect crop choice and fumigation decisions made by growers and consider how the decisions of long-term growers (whom we call "owners") differ from those of short-term growers (whom we call "renters"). We examine 
whether existing renter contracts internalize the intertemporal externality that a renter's decisions today impose on future renters and the landowner, and analyze the implications of renting versus owning land on welfare.

Although contracts can be a potential method for internalizing an externality between different parties, our empirical results in Carroll et al. (2017a) show that existing rental contracts do not fully internalize the intertemporal externality imposed by renters on future renters and the landowner. This outcome may be because of the relatively recent development of the disease and knowledge of its causes, more restrictive contracts not being the norm, the possibility of land unknowingly being contaminated before rental, or difficulty in enforcing or monitoring aspects of the contract such as whether boots and equipment are washed between fields.

In addition to the intertemporal externality, a second externality that arises due to $\mathrm{V}$. wilt is a supply chain externality between companies selling spinach seed and growers who may lettuce. Growers wish to protect their fields from V. wilt, but they cannot easily prevent introduction of the disease by spinach seeds when spinach is planted without incurring testing costs and cleaning fees. Currently, seed companies are unwilling to test or clean spinach seeds, especially as spinach producers are not affected by this disease. Thus, decisions made by seed companies regarding whether and how much to test or clean spinach seeds impose a supply chain externality on growers.

In Carroll et al. (2017b), we analyze the supply chain externality between growers and seed companies. We calculate the benefits to growers from testing and cleaning spinach seed by simulating growers' optimal decisions and welfare under different levels of seed testing and cleaning. We then estimate the spinach seed company's cost to testing and cleaning spinach seeds in order to reduce the level of microsclerotia, and compare the spinach seed company's cost to the grower's benefits. Because seed cleaning cost data are not available, we use several functional forms and parameters to estimate potential cost functions. We then use the benefits and costs to determine the welfare maximizing level of seed testing and 
cleaning.

According to our results in Carroll et al. (2017b), using data over the entire time period, we find that a cooperative solution would increase welfare, and in most cases, a cooperative solution would require that the spinach seed company engage in more spinach seed testing and cleaning than in the status quo. Our work regarding the supply chain externality between seed companies and growers sheds light on how treatment of spinach seeds could potentially reduce externalities between seed companies and growers.

Crop diseases and how they are managed can have a large impact on agricultural productivity. Externalities due to V. wilt that arise with renters, and between seed companies and growers have important implications for the management of $\mathrm{V}$. wilt in particular, and also for the management of diseases in agriculture in general. 


\section{References}

Abbring, J. 2010. "Identification of Dynamic Discrete Choice Models." Annual Review of Economics 2:367-394.

Aguirregabiria, V., and A. Luengo. 2016. "A Microeconometric Dynamic Structural Model of Copper Mining Decisions." Working Paper, Available < http://aguirregabiria.net/ wpapers/copper_mining $\cdot$ pdf $>$.

Atallah, S., M. Gomez, J. Conrad, and N. JP. 2015. "A Plant-Level, Spatial, Bioeconomic Model of Plant Disease, Diffusion, and Control: Grapevine Leafroll Disease." American Journal of Agricultural Economics 97:199-218.

Atallah, Z., R. Hayes, and K. Subbarao. 2011. "Fifteen Years of Verticillium Wilt of Lettuce in America's Salad Bowl: A Tale of Immigration, Subjugation, and Abatement." Plant Disease 95:784-792.

Atallah, Z., K. Maruthachalam, L. Toit, S. Koike, R. Michael Davis, S. Klosterman, R. Hayes, and K. Subbarao. 2010. "Population Analyses of the Vascular Plant Pathogen Verticillium dahliae Detect Recombination and Transcontinental Gene Flow." Fungal Genetics and Biology 47:416-422.

California Department of Pesticide Regulation. 2010. "Department of Pesticide Regulation Announces Work Group to Identify Ways to Grow Strawberries without Fumigants." Available <http://www.cdpr.ca.gov/docs/pressrls/2012/120424.htm>.

Carlson, G.A., and C.E. Main. 1976. "Economics of Disease-Loss Management." Annual Review of Phytopathology 14:381-403.

Carroll, C.L., C.A. Carter, R.E. Goodhue, and C.-Y. C. Lin Lawell. 2017a. "The Economics of Decision-Making for Crop Disease Control." Working Paper, University of California at Davis. 
—. 2017b. "Supply Chain Externalities and Agricultural Disease." Working Paper, University of California at Davis.

De Pinto, A., and G.C. Nelson. 2009. "Land Use Change with Spatially Explicit Data: A Dynamic Approach." Environmental and Resource Economics 43:209-229.

du Toit, L., M. Derie, and P. Hernandez-Perez. 2005. "Verticillium Wilt in Spinach Seed Production." Plant Disease 89:4-11.

du Toit, L., and P. Hernandez-Perez. 2005. "Efficacy of Hot Water and Chlorine for Eradication of Cladosporium variabile, Stemphylium botryosum, and Verticillium dahliae from Spinach Seed." Plant Disease 89:1305-1312.

Duressa, D., G. Rauscher, S.T. Koike, B. Mou, R.J. Hayes, K. Maruthachalam, K.V. Subbarao, and S.J. Klosterman. 2012. "A Real-Time PCR Assay for Detection and Quantification of Verticillium dahliae in Spinach Seed." Phytopathology 102:443-451.

Fradin, E.F., and B.P.H.J. Thomma. 2006. "Physiology and Molecular Aspects of Verticillium Wilt Diseases Caused by V. dahliae and V. albo-atrum." Molecular Plant Pathology 7:7186.

Gomez, M.I., H.M. Nunez, and H. Onal. 2009. "Economic Impacts of Soybean Rust on the US Soybean Sector." 2009 Annual Meeting, July 26-28, 2009, Milwaukee, Wisconsin No. 49595, Agricultural and Applied Economics Association.

Hueth, D., and U. Regev. 1974. "Optimal Agricultural Pest Management with Increasing Pest Resistance." American Journal of Agricultural Economics 56:543-552.

IPC. 2003. "International Phytosanitary Certificate No. 4051."

Johansson, R.C., M. Livingston, J. Westra, and K.M. Guidry. 2006. "Simulating the U.S. Impacts of Alternative Asian Soybean Rust Treatment Regimes." Agricultural and Resource Economics Review 35:116-127. 
Lin Lawell, C.-Y. C. 2017. "Wind Turbine Shutdowns and Upgrades in Denmark: Timing Decisions and the Impact of Government Policy." Working Paper, University of California at Davis.

Magnac, T., and D. Thesmar. 2002. "Identifying Dynamic Discrete Choice Processes." Econometrica 70:801-816.

Maruthachalam, K., S.J. Klosterman, A. Anchieta, B. Mou, and K.V. Subbarao. 2013. "Colonization of Spinach by Verticillium dahliae and Effects of Pathogen Localization on the Efficacy of Seed Treatments." Phytopathology 103:268-280.

McKee, G.J., R.E. Goodhue, F.G. Zalom, C.A. Carter, and J.A. Chalfant. 2009. "Population Dynamics and the Economics of Invasive Species Management: The Greenhouse Whitefly in California-Grown Strawberries." Journal of Environmental Management 90:561-570.

Moffitt, L., D. Hall, and C. Osteen. 1984. "Economic Thresholds Under Uncertainty with Application to Corn Nematode Management." Southern Journal of Agricultural Economics $16: 151-157$.

Monterey County Agricultural Commissioner. 2015. "Crop Reports and Economic Contributions." Available <http://www.co.monterey.ca.us/government/ departments-a-h/agricultural-commissioner/forms-publications/ crop-reports-economic-contributions $>$.

National Agricultural Statistics Service. 2015. "California Agricultural Statistics: 2013 Crop Year." Available <http://www.nass.usda.gov/Statistics_by_State/ California/Publications/California_Ag_Statistics/index.asp>.

Noailly, J. 2008. "Coevolution of Economic and Ecological Systems." Journal of Evolutionary Economics 18:1-29. 
Palm, M.E. 2001. "Systematics and the Impact of Invasive Fungi on Agriculture in the United States." BioScience 51:141-147.

Rapson, D. 2014. "Durable Goods and Long-run Electricity Demand: Evidence from Air Conditioner Purchase Behavior." Journal of Environmental Economics and Management 68:141-160.

Rossman, A. 2009. "The Impact of Invasive Fungi on Agricultural Ecosystems in the United States." Biological Invasions 11:97-107.

Rothwell, G., and J. Rust. 1997. "On the Optimal Lifetime of Nuclear Power Plants." Journal of Business \&6 Economic Statistics 15:195-208.

Rust, J. 1988. "Maximum Likelihood Estimation of Discrete Control Processes." SIAM Journal on Control and Optimization 26:1006-1024.

-. 1987. "Optimal Replacement of GMC Bus Engines: An Empirical Model of Harold Zurcher." Econometrica: Journal of the Econometric Society 55:999-1033.

—. 1994. "Structural Estimation of Markov Decision Processes." In R. Engle and D. McFadden, eds. Handbook of Econometrics. Amsterdam: North-Holland, vol. 4, pp. 3081-3143.

Scott, P.T. 2013. "Dynamic Discrete Choice Estimation of Agricultural Land Use." Working Paper, Available <http: //www.ptscott.com $>$.

Shetty, K., K. Subbarao, O. Huisman, and J. Hubbard. 2000. "Mechanism of BroccoliMediated Verticillium Wilt Reduction in Cauliflower." Phytopathology 90:305-310.

Short, D.P.G., S. Gurung, S.T. Koike, S.J. Klosterman, and K.V. Subbarao. 2015. "Frequency of Verticillium Species in Commercial Spinach Fields and Transmission of $V$. dahliae from Spinach to Subsequent Lettuce Crops." Phytopathology 105:80-90. 
Subbarao, K.V., and J.C. Hubbard. 1996. "Interactive Effects of Broccoli Residue and Temperature on Verticillium dahliae Microsclerotia in Soil and on Wilt in Cauliflower." Phytopathology 86:1303-1310.

Subbarao, K.V., J.C. Hubbard, and S.T. Koike. 1999. "Evaluation of Broccoli Residue Incorporation into Field Soil for Verticillium Wilt Control in Cauliflower." Plant Disease $83: 124-129$.

Timmins, C. 2002. "Measuring the Dynamic Efficiency Costs of Regulators' Preferences: Municipal Water Utilities in the Arid West." Econometrica 70:603-629.

United States Environmental Protection Agency. 2012a. "Critical Use Exemption Information." Available <http://www.epa.gov/ozone/mbr/cueinfo.html $>$.

-. 2012b. "The Phaseout of Methyl Bromide." Available < http://www.epa.gov/ozone/ $\mathrm{mbr} /$ index.html $>$.

van Kooten, G.C., W.P. Weisensel, and D. Chinthammit. 1990. "Valuing Tradeoffs between Net Returns and Stewardship Practices: The Case of Soil Conservation in Saskatchewan." American Journal of Agricultural Economics 72:104-113.

Weisensel, W.P., and G.C. van Kooten. 1990. "Estimation of Soil Erosion Time Paths: The Value of Soil Moisture and Topsoil Depth Information." Western Journal of Agricultural Economics 15:63-72.

Wu, J. 2001. "Optimal Weed Control Under Static and Dynamic Decision Rules." Agricultural Economics 25:119-130.

Xiao, C., and K. Subbarao. 1998. "Relationships Between Verticillium dahliae Inoculum Density and Wilt Incidence, Severity, and Growth of Cauliflower." Phytopathology 88:11081115. 
Figure 1

Marketing year average prices per acre

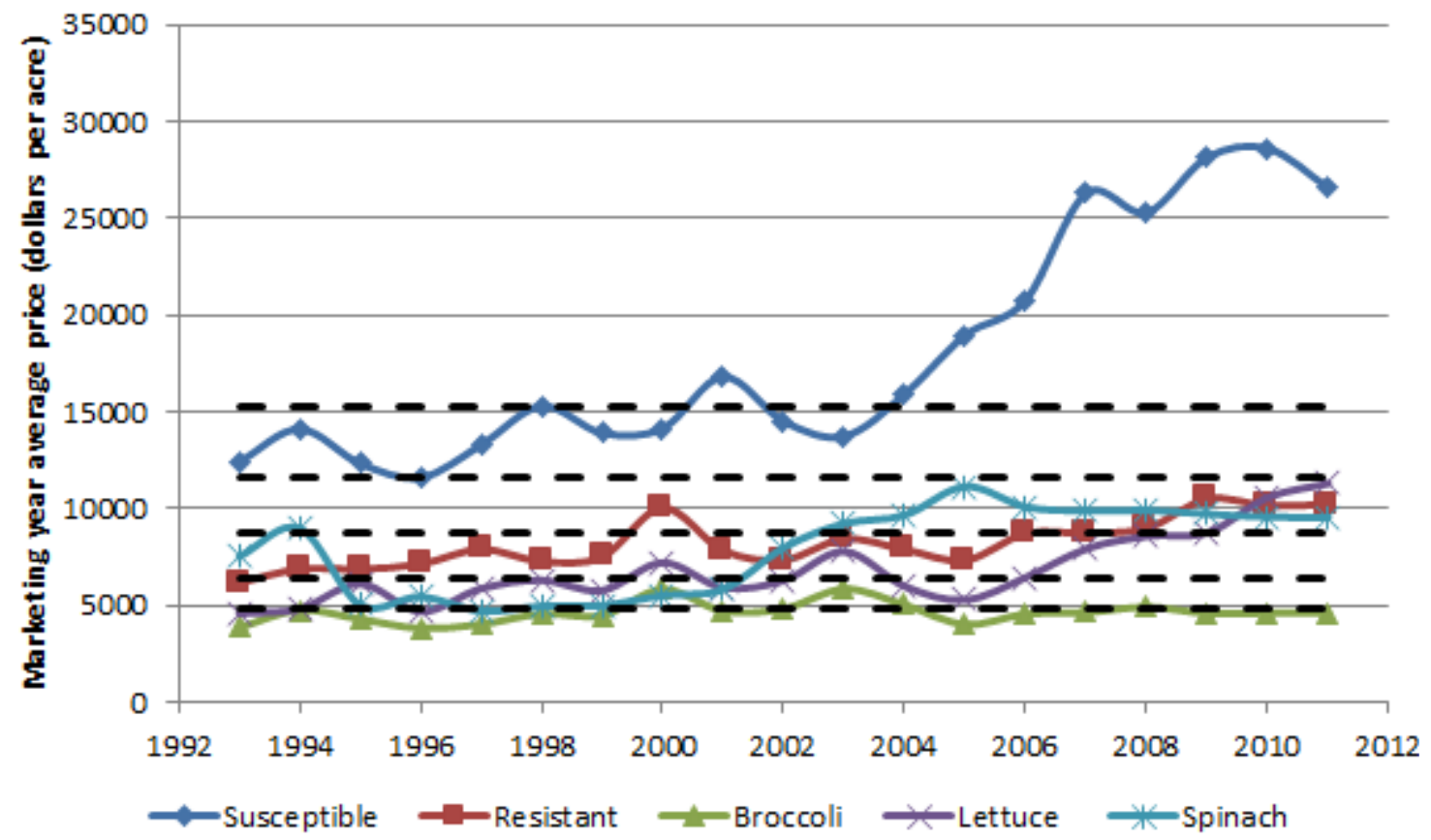

Note: Black dashed lines delineate the bins used to discretize the marketing year average price. 
Table 1

Summary statistics for state variables

\begin{tabular}{lcccc}
\hline \hline & Mean & Std. Dev. & Minimum & Maximum \\
\hline Spinach dummy & 0.0285 & 0.1665 & 0 & 1 \\
Methyl bromide today dummy & 0.0033 & 0.0577 & 0 & 1 \\
Broccoli dummy & 0.0606 & 0.2385 & 0 & 1 \\
Lettuce *Methyl bromide history & 0.0229 & 0.1602 & 0 & 3 \\
Lettuce *Broccoli history & 1.1709 & 1.8277 & 0 & 12 \\
Spinach *Methyl bromide history & 0.0015 & 0.0431 & 0 & 2 \\
Spinach *Broccoli history & 0.0397 & 0.3701 & 0 & 10 \\
Lettuce today dummy & 0.6379 & 0.4806 & 0 & 1 \\
Susceptible price*Susceptible harvest & 5.0660 & 1.4914 & 0 & 6 \\
Resistant price*Resistant harvest & 1.8748 & 1.6125 & 0 & 4 \\
Broccoli price*Broccoli harvest & 1.1742 & 0.5082 & 0 & 2 \\
Lettuce price*Lettuce harvest & 1.9552 & 1.1004 & 0 & 4 \\
Spinach price*Spinach harvest & 2.5268 & 1.4709 & 0 & 4 \\
\hline
\end{tabular}

Notes: Number of observations: 25,789. For each crop, the harvest month dummy variable for that crop is equal to one in months during which that crop may be harvested, and zero in months during which that crop is not harvested (i.e., winter months for most crops). 
Figure 2

Actual fraction of grower-months in each action

1

0.9

0.8

0.7

0.6

0.5

0.4

0.3

0.2

0.1

0
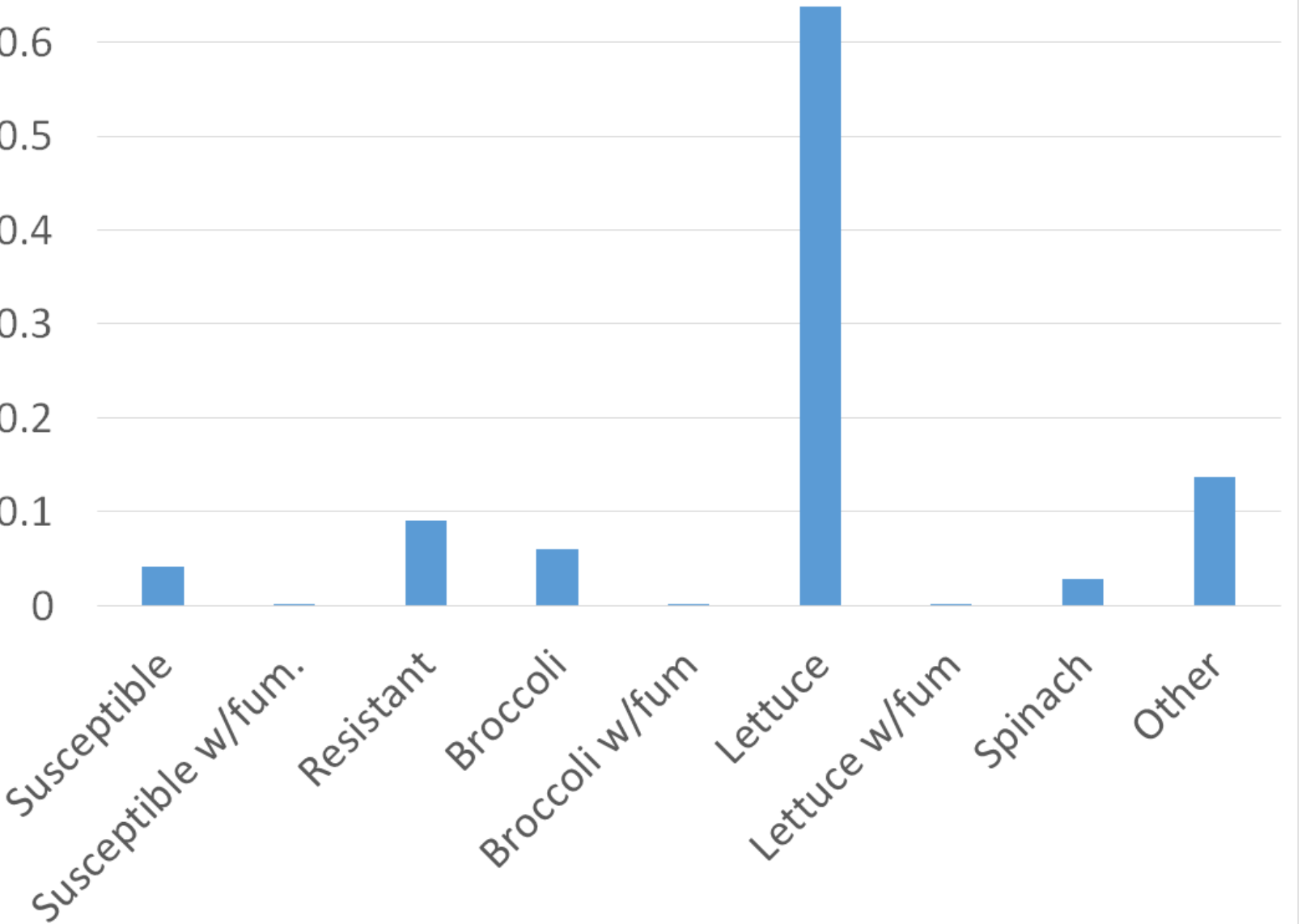<smiles>[Ge]=[Ge]</smiles><smiles>C1CO[Co]C1</smiles> 
Figure 3

Fraction of grower-months in each action type by month of year

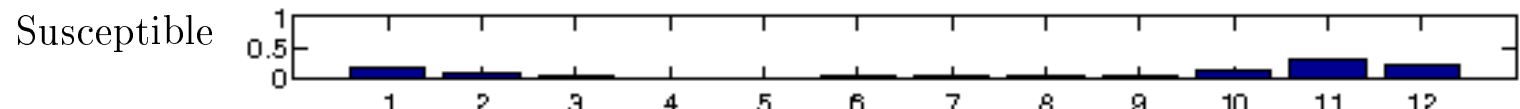

Sus. w/fum
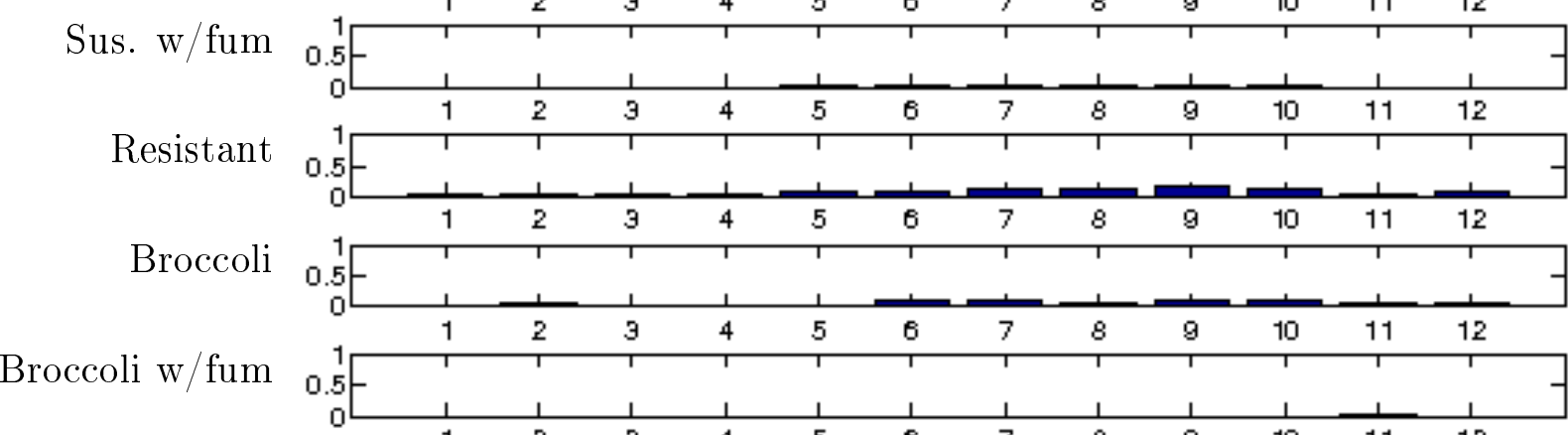

Lettuce

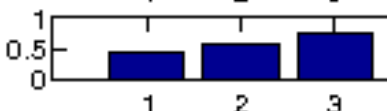

Lettuce w/fum

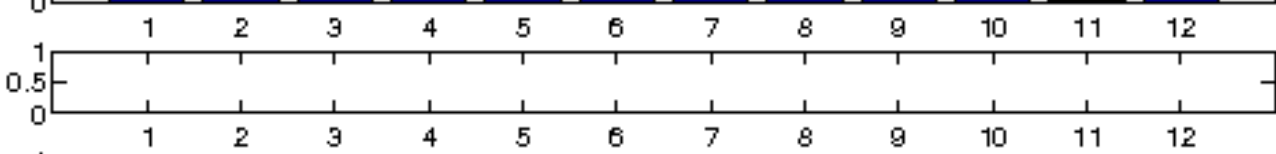

Spinach
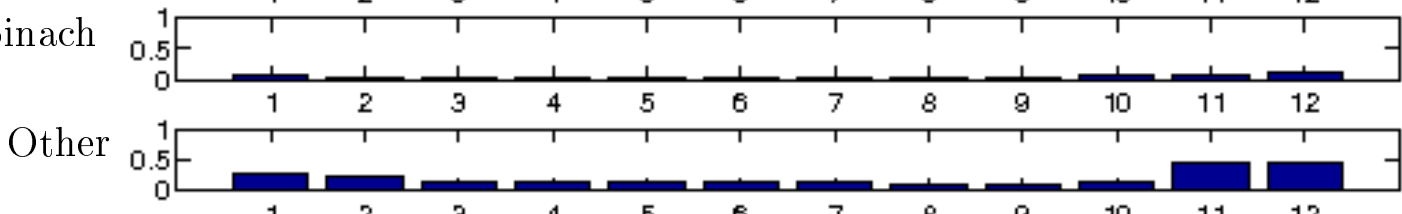

Month 
Figure 4

Actual fraction of grower-months for each action type by year

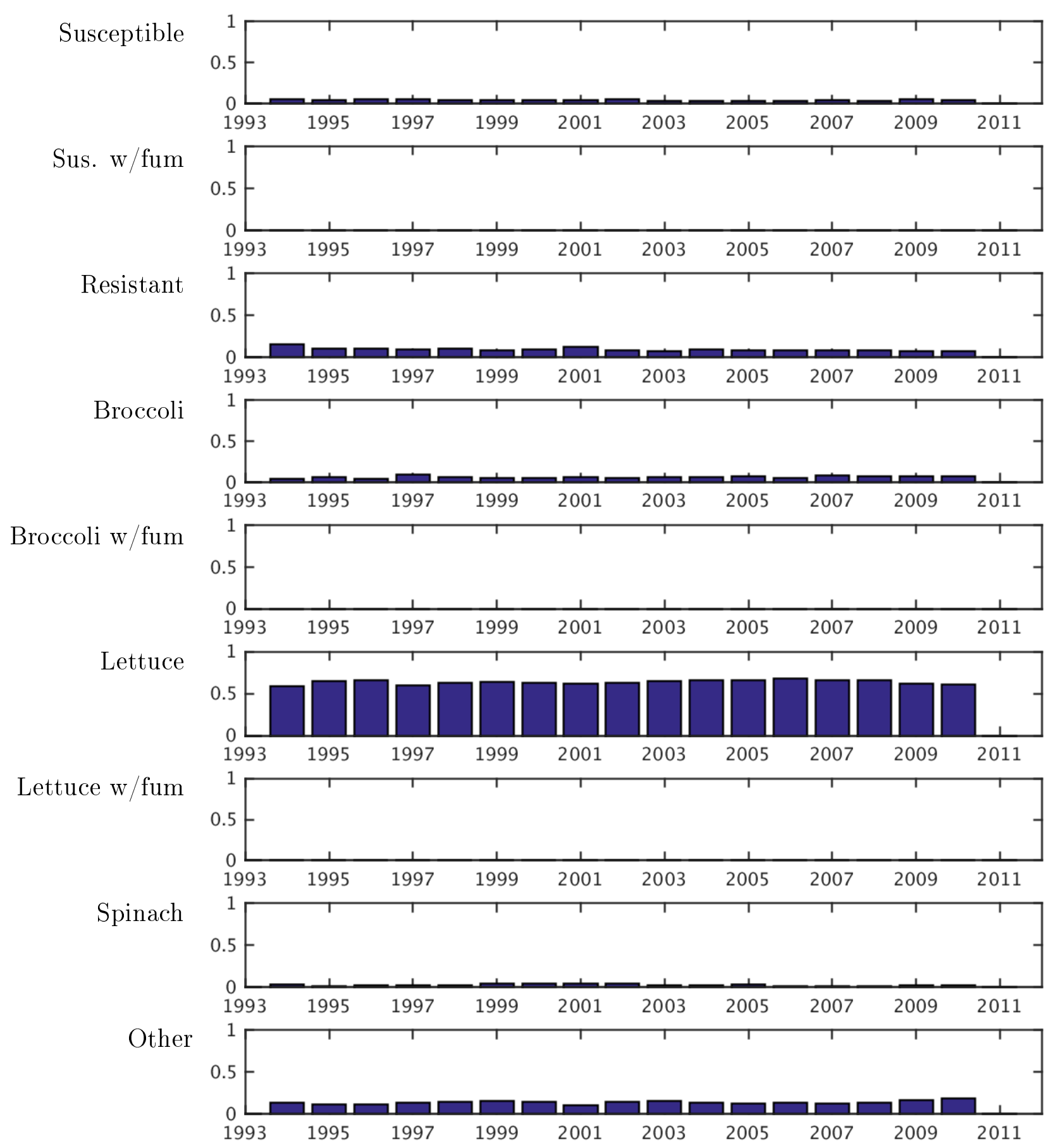

Year 
Table 2

Results for long-term growers

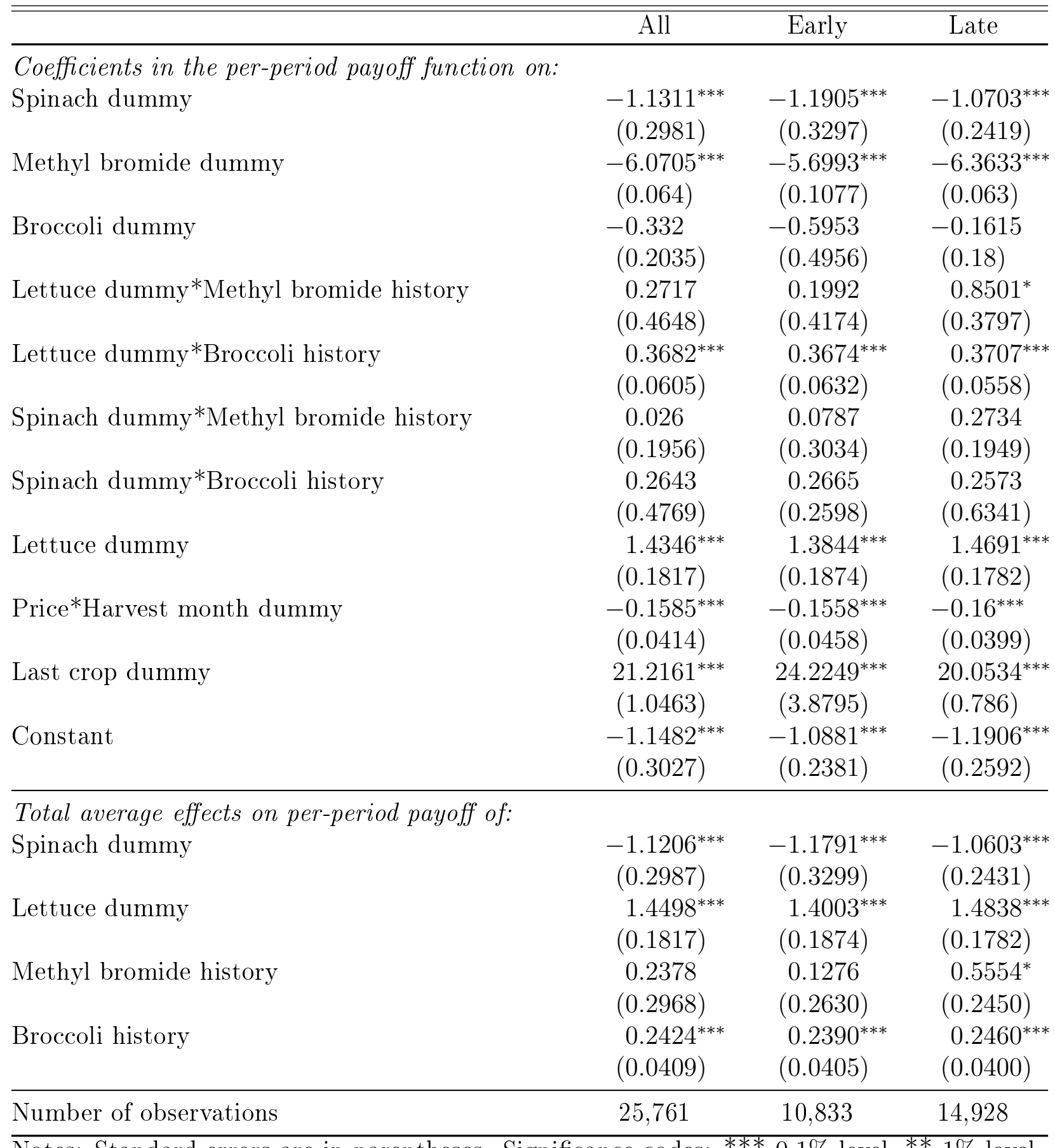

Notes: Standard errors are in parentheses. Significance codes: ${ }^{* * *} 0.1 \%$ level, ${ }^{* *} 1 \%$ level, * $5 \%$ level, $\dagger 10 \%$ level. 
Table 3

Normalized average present discounted grower welfare per grower-month

\begin{tabular}{lccc}
\hline \hline & All & Early & Late \\
\hline Grower Welfare (per grower-month) & 100 & 117.3475 & 92.7063 \\
& $(5.0957)$ & $(19.2088)$ & $(3.4884)$ \\
\hline
\end{tabular}

Note: The average grower welfare per grower per month is normalized so that the average welfare per grower per month over the entire time period ('all') is 100. Standard errors in parentheses. All welfare values are significant at a $0.1 \%$ level. 
Figure 5

Normalized average per-month (per-period) grower benefits from disease mitigation

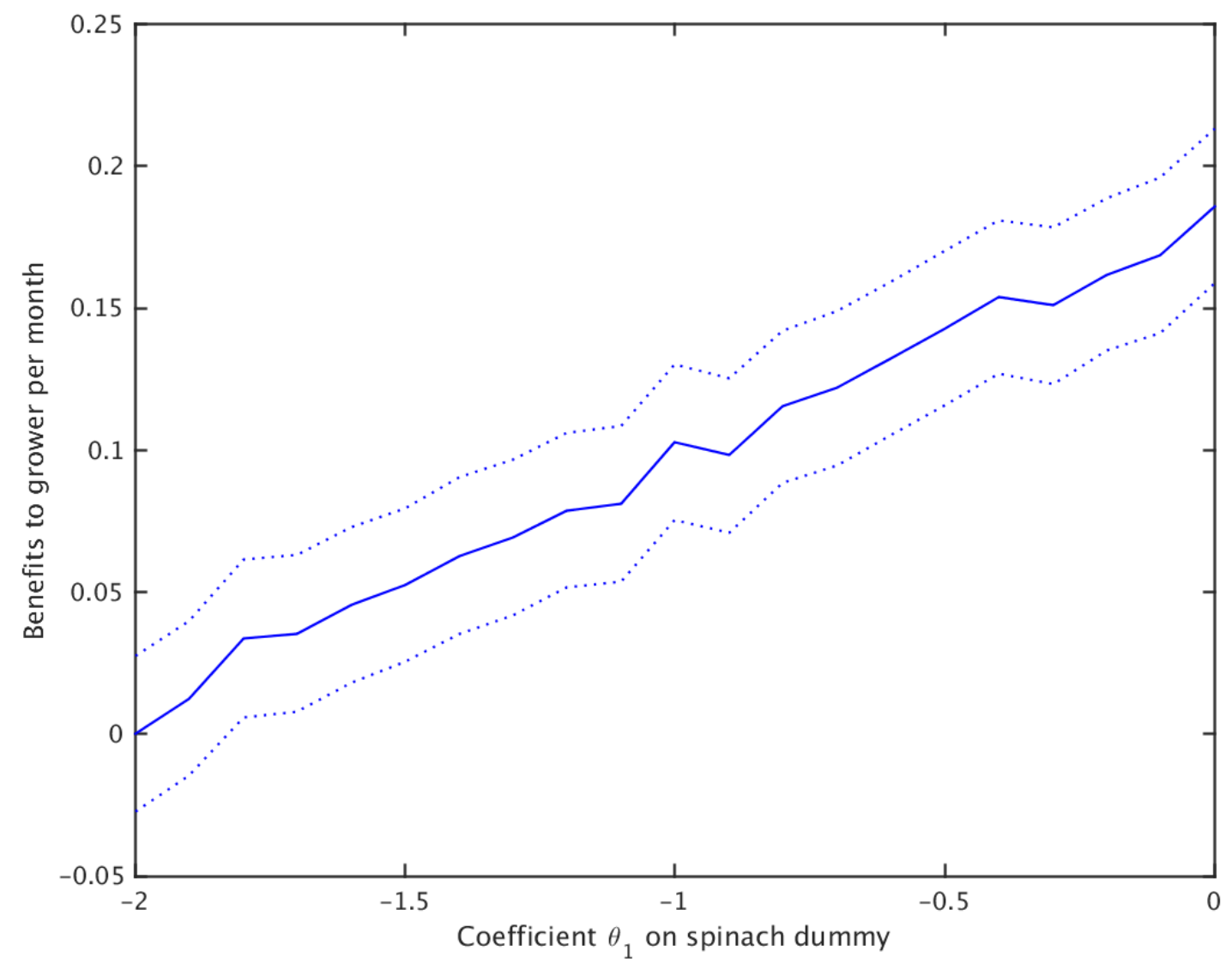

Notes: The less negative the spinach dummy coefficient $\theta_{1}$, the less severe the disease. We calculate the average benefits to the grower from mitigating the disease by subtracting the average grower welfare per month when the spinach dummy coefficient $\theta_{1}$ is an extremely severe -2.00 from the average grower welfare per month at each value of the spinach dummy coefficient. In other words, we normalize the average grower welfare per month when the spinach dummy coefficient $\theta_{1}$ is an extremely severe -2.00 to 0 . Benefits are averaged over 100 simulations. Dotted blue lines indicate the $95 \%$ confidence interval, which is calculated using a nonparametric bootstrap. 
Figure 6

Simulated mean fraction of grower-months in each action when spinach dummy coefficient $\theta_{1}$ equals 0

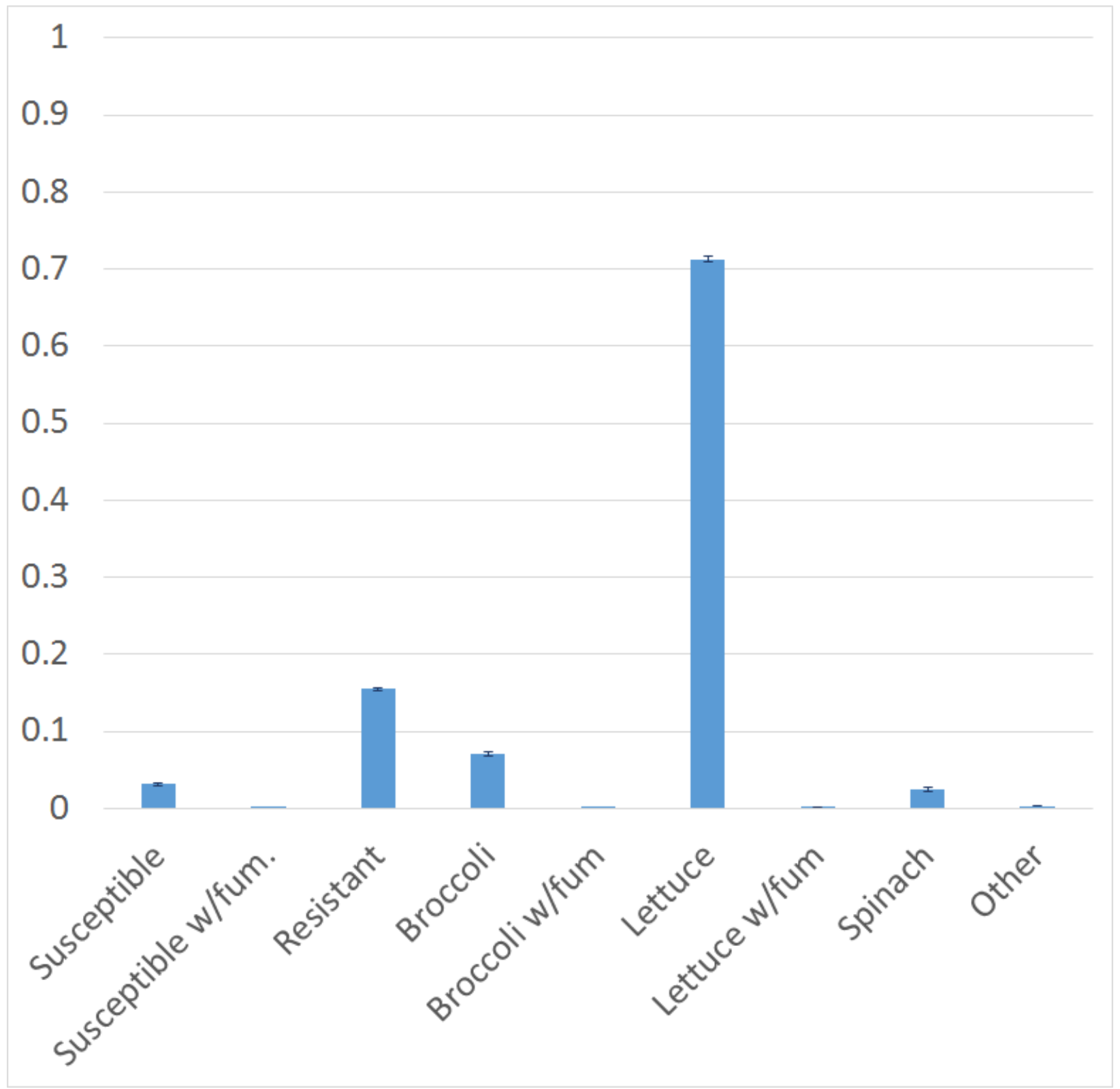

Notes: The fraction of grower-months in each action is averaged over 25 simulations. Error bars represent the $95 \%$ confidence interval, which is calculated using a nonparametric bootstrap. 
Figure 7

Simulated mean fraction of grower-months in each action when spinach dummy coefficient $\theta_{1}$ equals -1.00

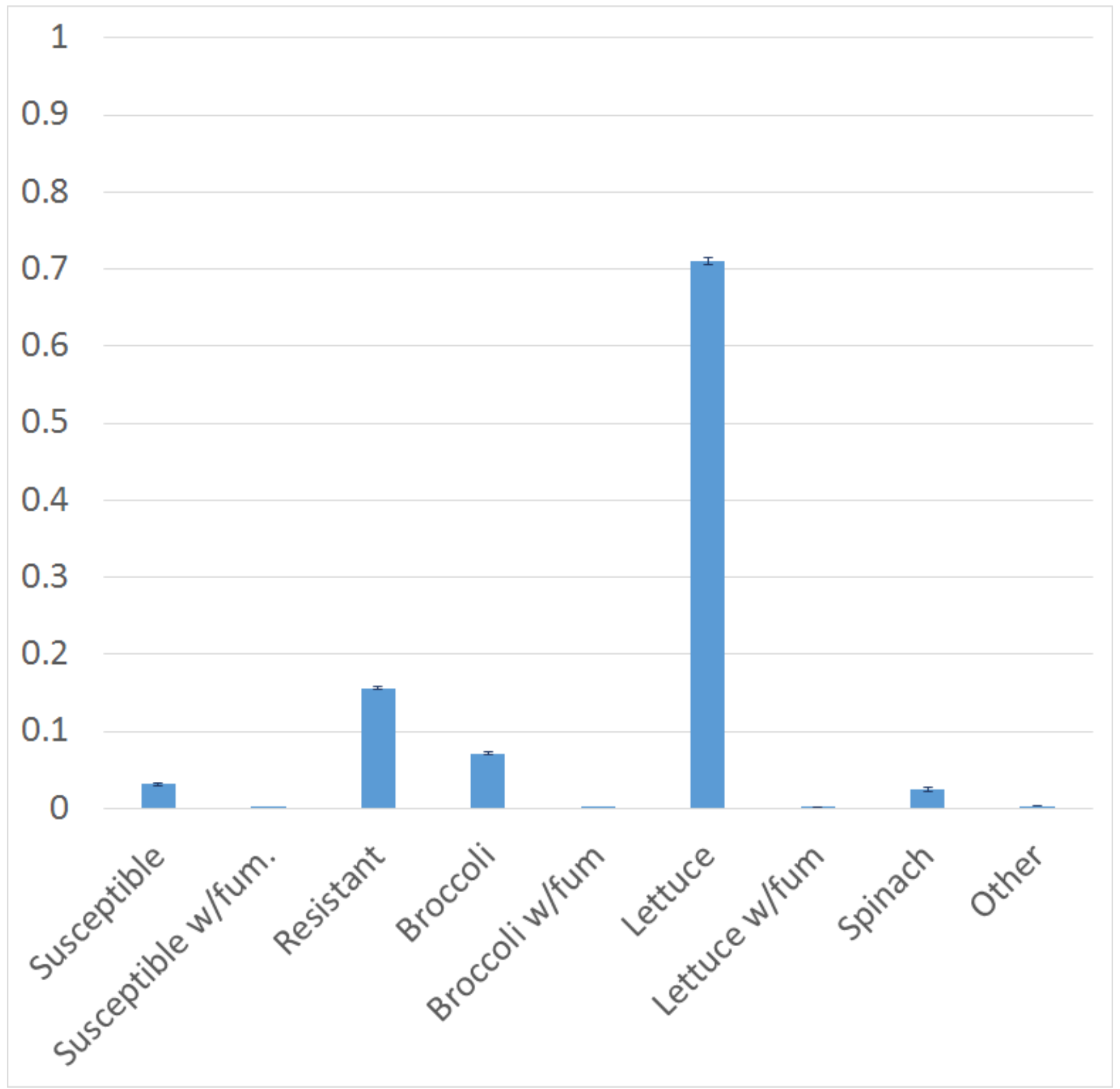

Notes: The fraction of grower-months in each action is averaged over 25 simulations. Error bars represent the $95 \%$ confidence interval, which is calculated using a nonparametric bootstrap. 
Figure 8

Simulated fraction of grower-months in each action type by month of year when spinach dummy coefficient $\theta_{1}$ equals 0
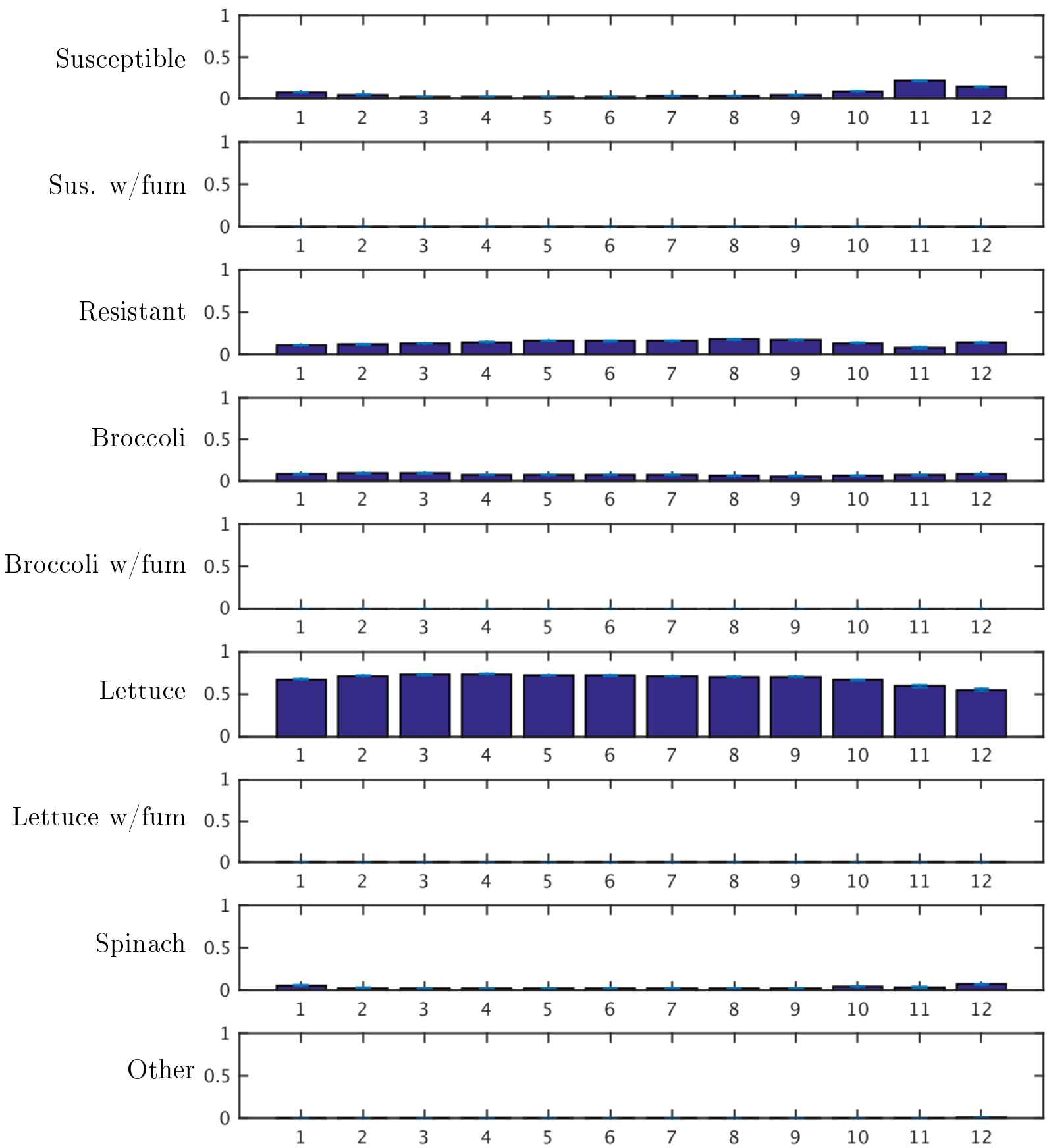

Month

Notes: The fraction of grower-months in each action by month of year is averaged over 25 simulations. Error bars represent the $95 \%$ confidence interval, which is calculated using a nonparametric bootstrap. 
Figure 9

Simulated fraction of grower-months in each action type by month of year when spinach dummy coefficient $\theta_{1}$ equals -1.00
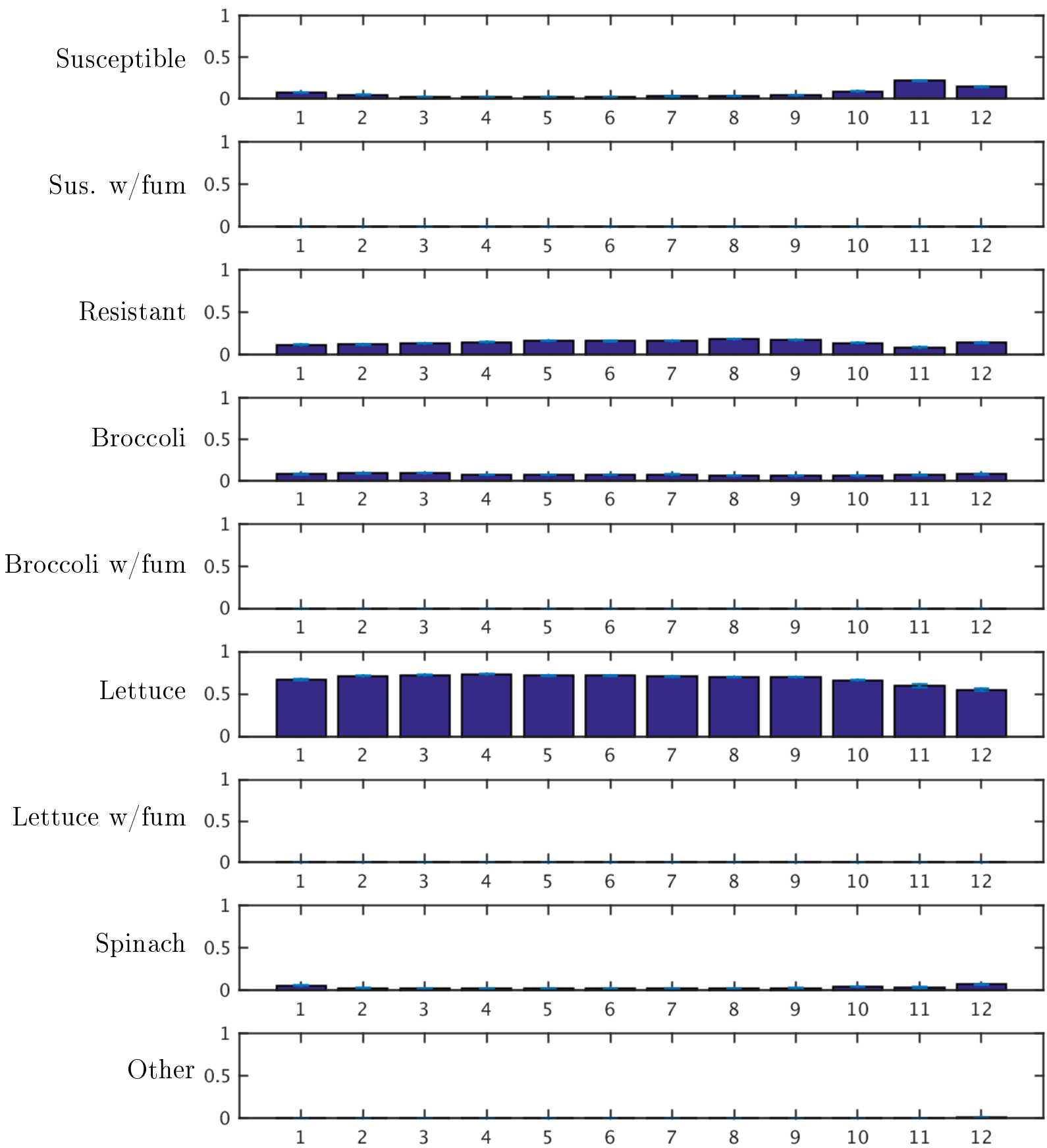

Month

Notes: The fraction of grower-months in each action by month of year is averaged over 25 simulations. Error bars represent the $95 \%$ confidence interval, which is calculated using a nonparametric bootstrap. 
Figure 10

Simulated fraction of grower-months in each action type by year when spinach dummy coefficient $\theta_{1}$ equals 0

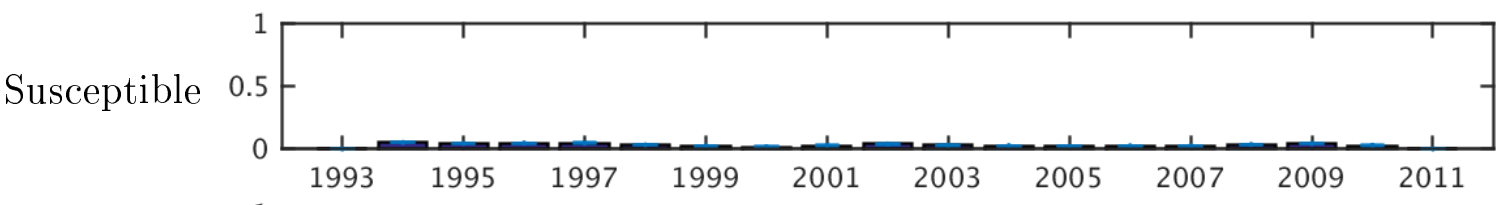

Sus. w/fum

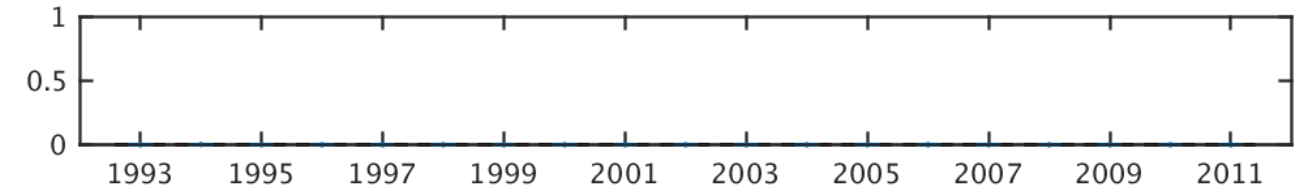

Resistant

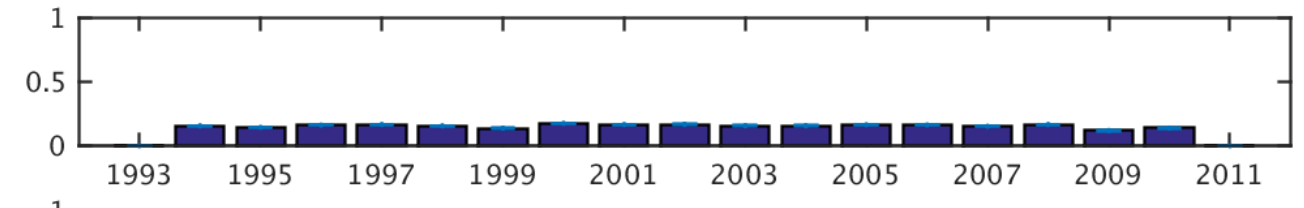

Broccoli

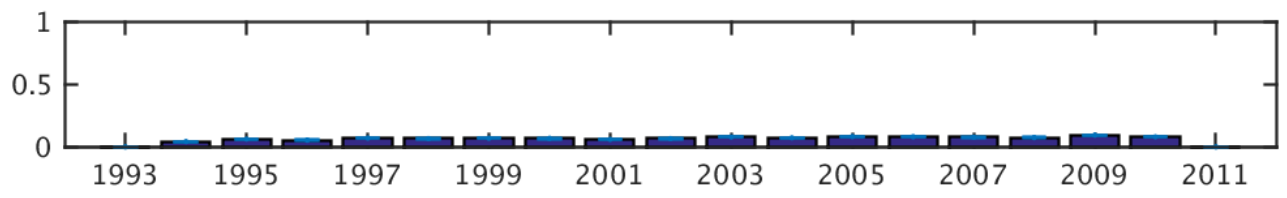

Broccoli w/fum

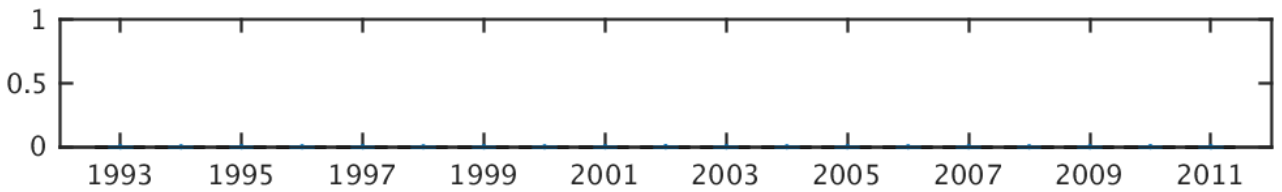

Lettuce

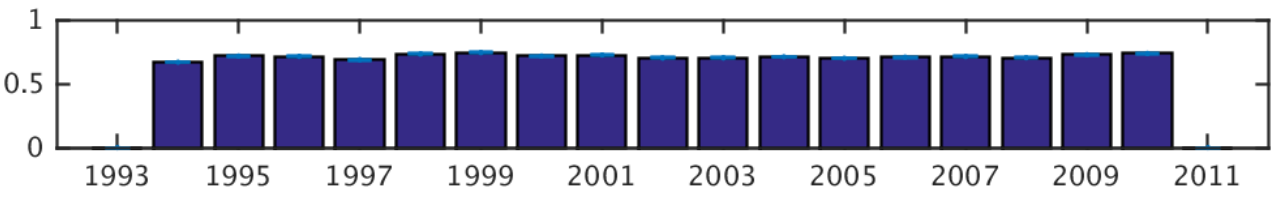

Lettuce $\mathrm{w} /$ fum

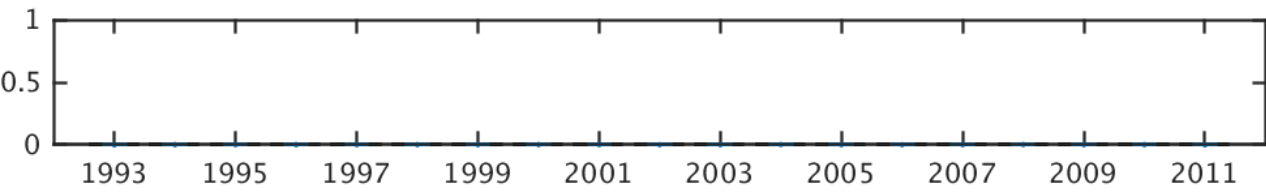

Spinach

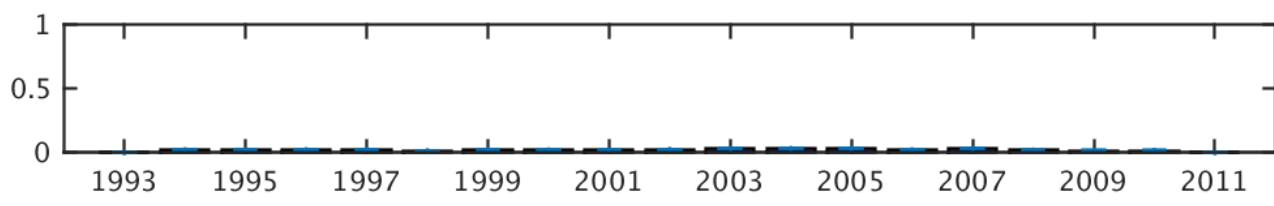

Other 0.5

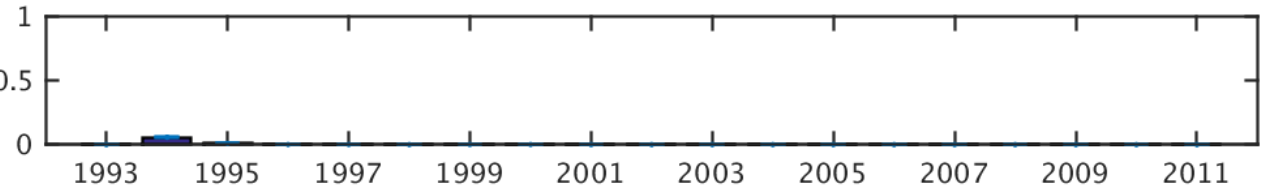

Year

Notes: The fraction of grower-months in each action by year is averaged over 25 simulations. Error bars represent the $95 \%$ confidence interval, which is calculated using a nonparametric bootstrap. 
Figure 11

Simulated fraction of grower-months in each action type by year when spinach dummy coefficient $\theta_{1}$ equals -1.00

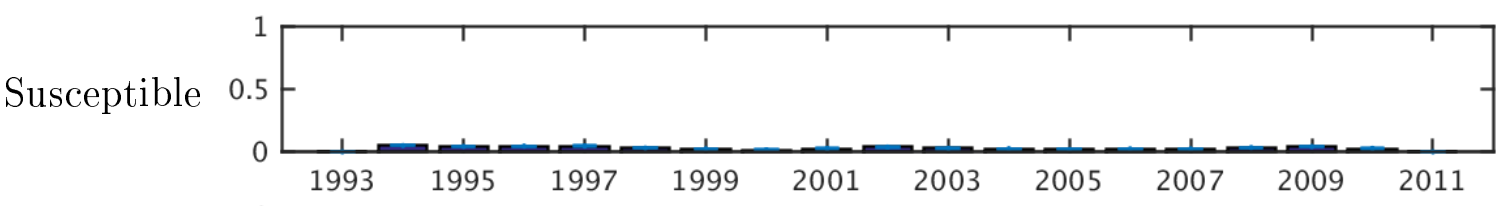

Sus. w/fum

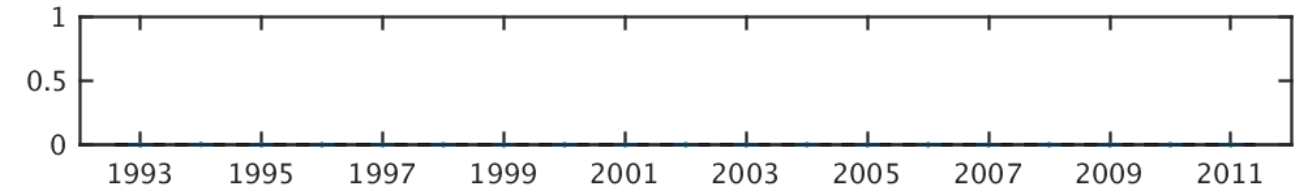

Resistant

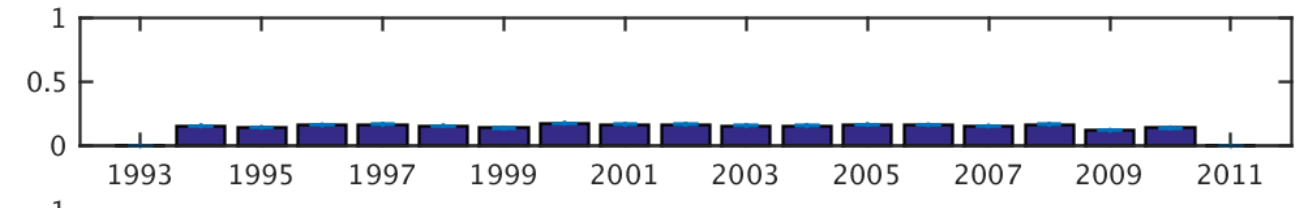

Broccoli

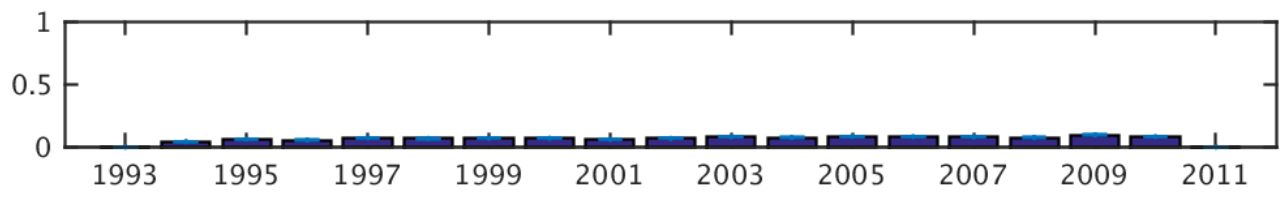

Broccoli w/fum

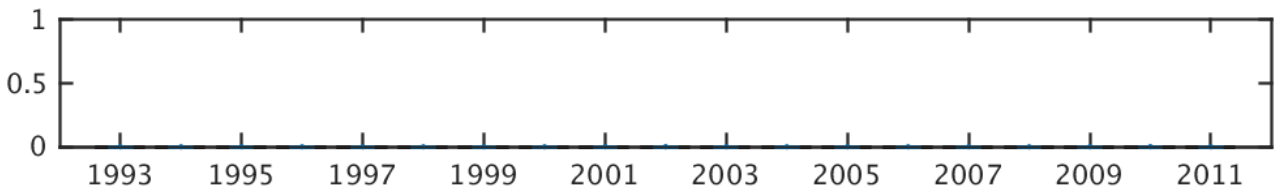

Lettuce

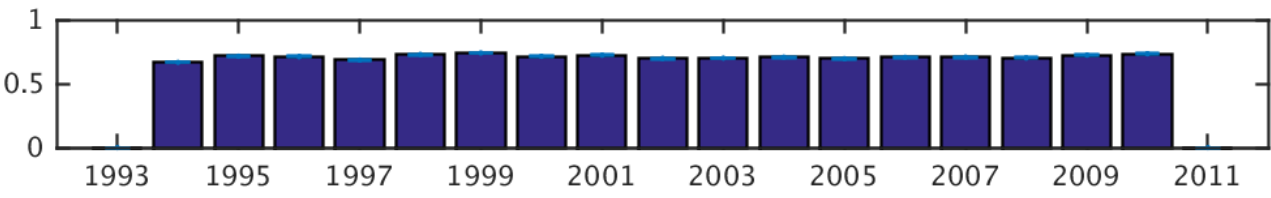

Lettuce $\mathrm{w} /$ fum

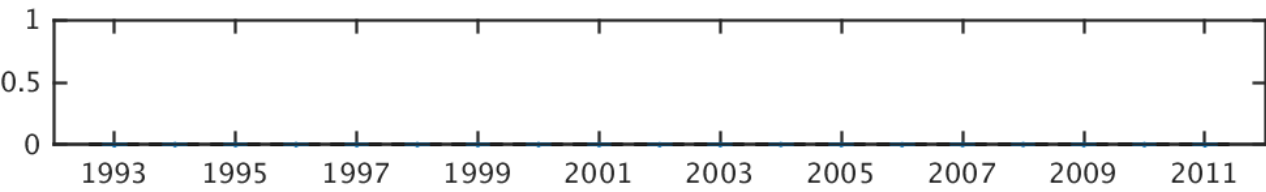

Spinach

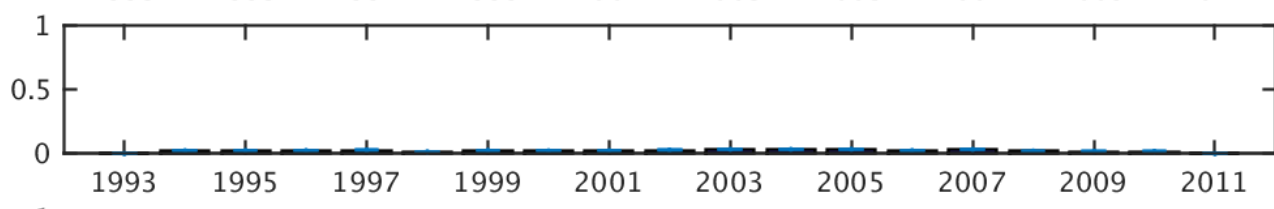

Other 0.5

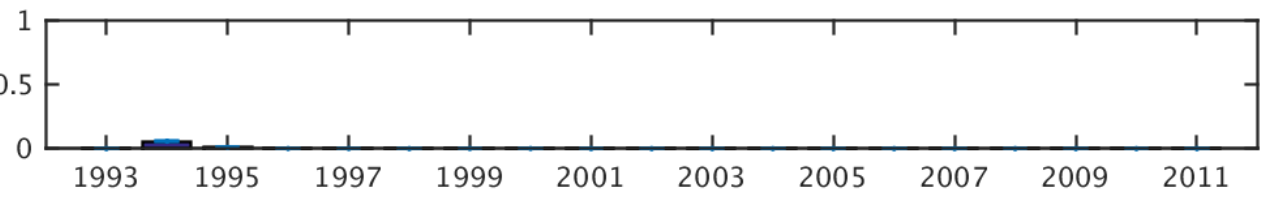

Year

Notes: The fraction of grower-months in each action by year is averaged over 25 simulations. Error bars represent the $95 \%$ confidence interval, which is calculated using a nonparametric bootstrap. 